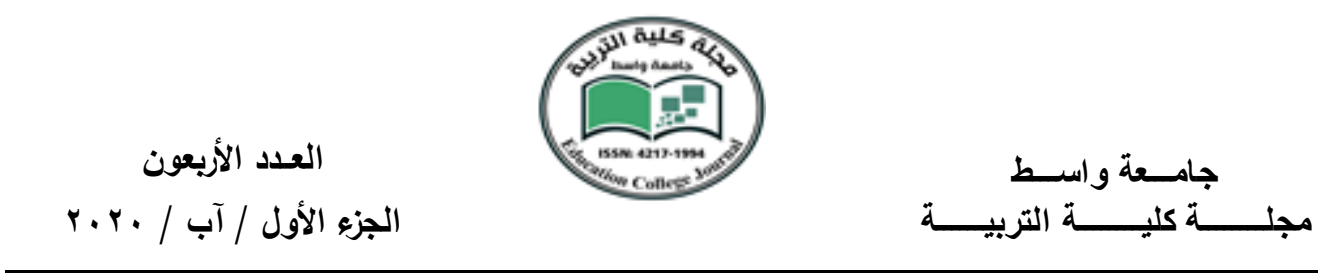

\title{
الهجرة القسرية وابعادها في وفيات الأطفال \\ دراسة ميدانية في مدينة أربيل
}

أ.مدد. فراس عباس فاضل البياتي

جامعة الوصل / كلية الآداب / قسم علم الاجتماع العاني

firasalbiaty@gmail.com

الماخصن

من المطوم أن العلاقة وثيقة بين عناصر النمو السكاني المتثلة بالهجرة والوفيات والخصوبة

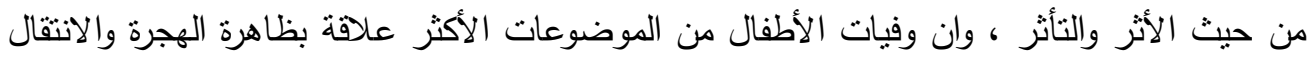

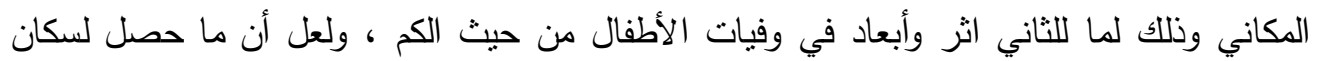

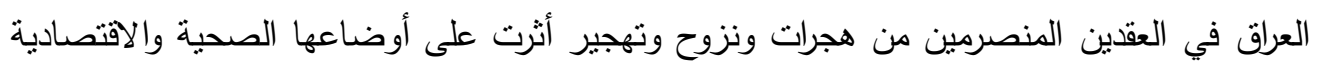

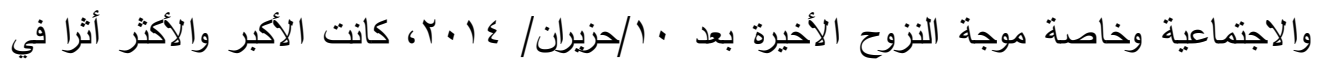

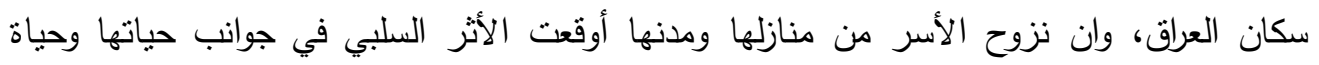

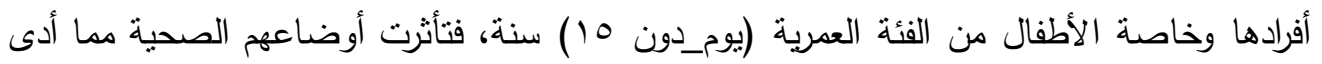

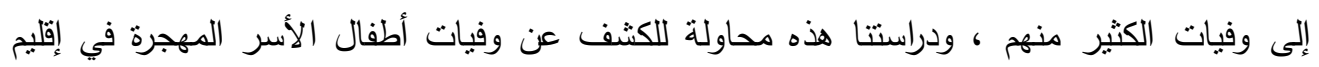

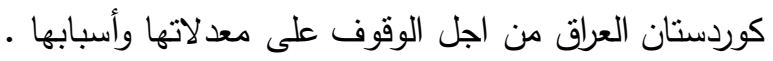
ضمت الدراسة إلى جانب المقامة ثلاثة مباحث، جاء الثاء الأول (الإطار الدنهجي للاراسة)،

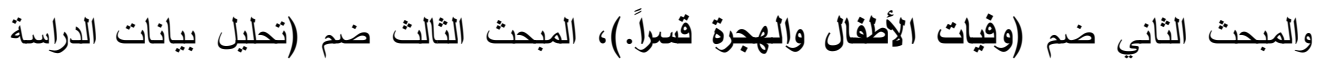

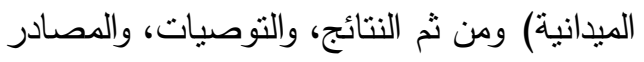
• أهداف البحث: لكل بحث هدف أو مجموعة أهداف، وأهداف بحثا تمثلت فيما بأتي:

1. التعرف على نسب وفيات الأطفال الأسر المهجرة في مدينة أربيل. r. الكثف عن الأوضاع الاجتماعية والاقتصادية والصحية للأسر المهجرة التي لها لها أطفال متوفين.

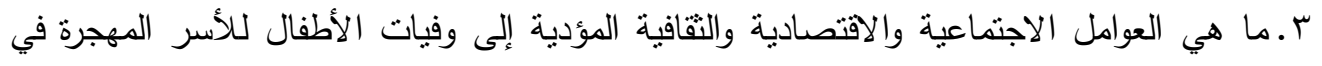

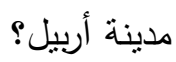

ع ـ توضيح العلاقة بين الهجرة ووفيات الأطفال في مدينة أربيل. ه ـ التعرف على أسباب وفيات أطفال الأسر المهجرة في مدينة أربيل. 


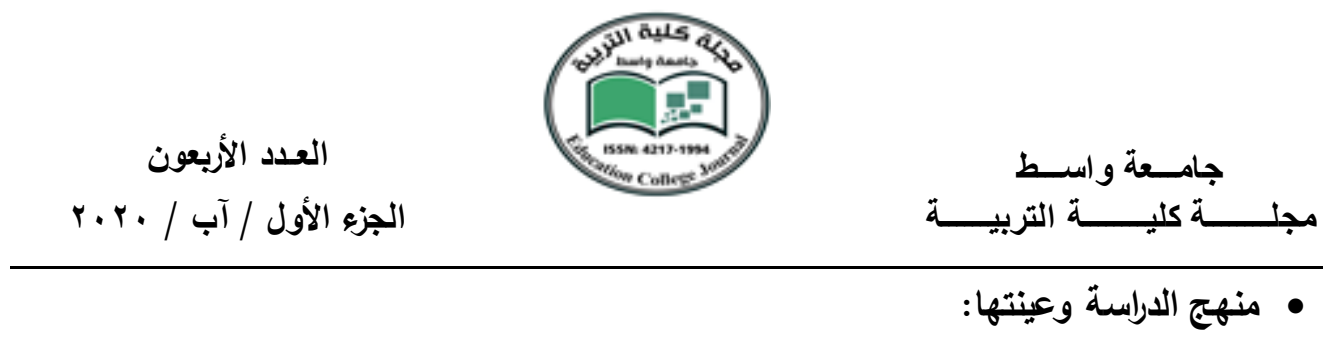

في محاولة بحث الظاهرة بشكل موضوعي وعلمي استخدم الباحث منهج المسح الاجتماعي

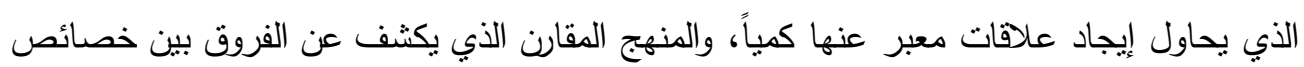
عينة الدراسة. اختار الباحث عينة تألفت من (Yr) أسرة، توفي أطفالها في الهجرة، وبالطريقة العشوائية البسيطة في مدينة أربيل .أستخدم الباحث في عطلية جمع البيانات والمعلومات (المقابلة، والاستبيان)

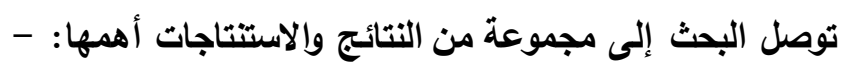

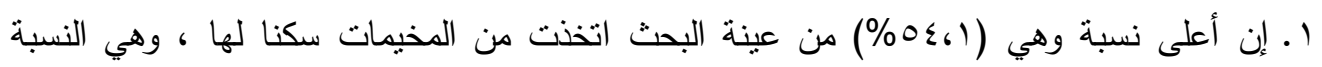

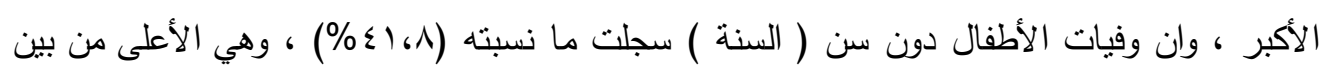

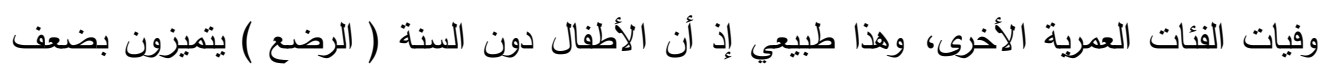
مقاومتهم للأمراض وضعف بنيتهم وسرعة تأثرهم بتقلبات البيئة الفيزيولوجية ، وإن نسب وفيات الإناث هي الأعلى في العينة بلغت ( 7،ـ1\%) وهي من النسب العالية قياسا بوفيات الذكور البالغة (

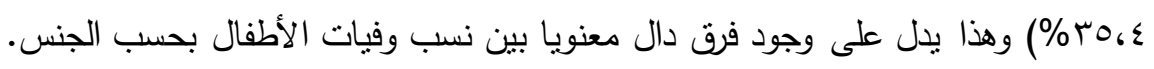

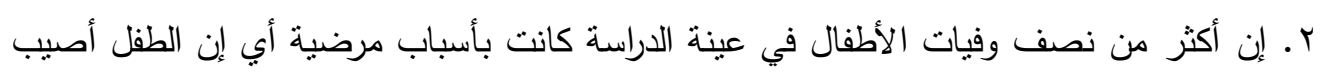

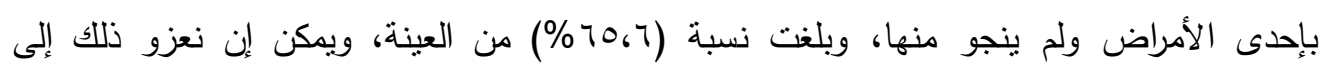
الأسباب الني سبق وان أشرنا اليها في الأسطر والصفحات السابقة الني تتمثل في ولني (عدم الإمكانية الاقتصادية للأسرة في علاج أطفالها، عدم توفر الرعاية الصحية في مناطق سكناها، انتشار الأوبئة الأنس والأمراض في المخيمات السكنية، قلة الوعي الصحي والنقافي للأسرة .... ودواليك).

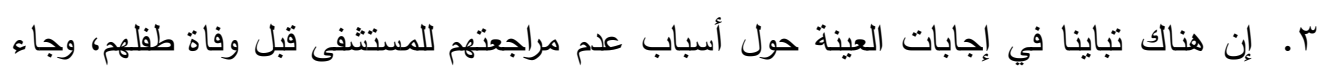
السبب (عدم وجود مستشفى في المخيم أو منطقة السكن) في المرتبة الأولى من التسلسل المرتبي لأسباب عدم مراجعة الأسرة للمستثفى قبل وفاة طفلها، وبلغت عدد الإجابات (• ع) إجابة. الكلمات المفتاحية : الأسرة، الوفيات، الهجرة ، النمو السكاني 


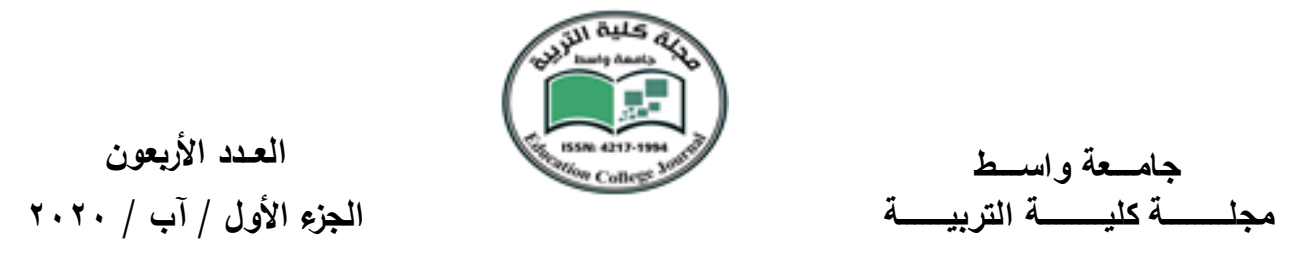

\section{Forced migration and its remoteness in child mortalty}

A field study in the city of Erbil

\section{Summary}

It is known that a close relationship between population growth of immigration and fertility and mortality in terms of impact and vulnerability to the elements, and that the deaths of children from the most topics related to the phenomenon of immigration and the transition spatial That is because of the second impact and dimensions of the deaths of children in terms of quantity, and perhaps that is what happened to the people of Iraq in the past two decades of migrations and displacement and displacement affected the health, economic and social conditions, especially the recent wave of displacement after 10 / June / 2014, was the largest and most impact on the Iraqi population, and that the exodus of families from their homes and cities have caused negative impact on aspects of their lives and the lives of its members, and especially the children of the age group (Aom_don 15) years, Vtothert health conditions which led to the deaths of many of them, and this study is an attempt to detect and infant mortality displaced families in the Kurdistan region of Iraq in order to stand on the rates and causes.

The study included along submitted three sections, came first (methodological framework for the study), and the second topic included (forced and child mortality and migration.), The third section included (field study data analysis) and then the results, and recommendations, and sources

-Research objectives: for each search target or group of targets, and objectives of our research were as follows:

. identify and child mortality rates displaced families in the city of Erbil.

rdisclosure of social, economic and health conditions of displaced families who have dead children.

.What are the social, economic and cultural factors leading to the deaths of children of displaced families in the city of Erbil?

. clarify the relationship between migration and child mortality in the city of Erbil.

.${ }^{\circ}$ identify the cause of death for children of displaced families in the city of Erbil. 


$$
\begin{aligned}
& \text { العدد الأربعون }
\end{aligned}
$$

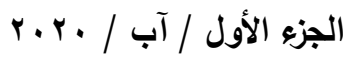

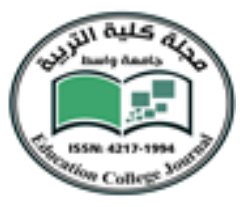

-Methodology of the study and appointed: Try Search phenomenon in an objective and scientific researcher used the social survey method, which tries to find relationships expressed quantitatively, and comparative approach that reveals the differences between the characteristics of the study sample. Researcher chose the sample consisted of 122 family, her children died in immigration, and simple random way in the city of Erbil. The researcher used in the process of collecting data and information (interview, questionnaire(

The research found a set of findings and conclusions, including- :

. The highest proportion which $(54.1 \%)$ of the sample taken from the camps housing them, the largest proportion, and that the deaths of children under the age of (the year) recorded a rate (41.8\%), the highest among maternal age groups the other, this is normal as the children under one year (infants) are characterized by the weakness of their resistance to disease and physical weakness and vulnerability to fluctuations in the physiological environment, and female mortality rates are the highest in the sample was $(64.6 \%)$, one of the high rates compared mortality adult males $(35,4 \%)$, and this indicates the presence of significant difference between the moral and child mortality rates by sex.

. rIf more than half the deaths of children in the study sample were the reasons for satisfying any child that was injured in one of the diseases did not escape them, and the percentage $(65.6 \%)$ of the sample, can be attributed to the reasons previously mentioned it in the lines and previous page which is the (lack of economic potential of the family in the treatment of children, lack of health care in the habitable zones, the spread of epidemics and diseases in residential camps, lack of health and cultural awareness of the family .... and forth.(

.rIf there is variation in the answers respondents about the reasons for not checking with the hospital before the death of their child, and was the reason (lack of a hospital in the camp or residential area) in the first rank of the hierarchical sequence of the reasons for non-family review of the hospital before the death of her child, and reached the number of responses (40) Answer.

Key words: family, mortality, migration, population growth 
العدد الأربعون

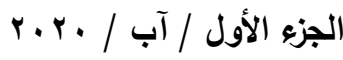

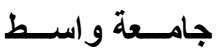

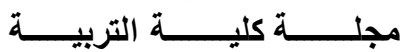

المقدمة

تعد وفيات الأطفال من الموضوعات التي نالت اهتمام الباحثين منذ القدم، وذلك لأهمية

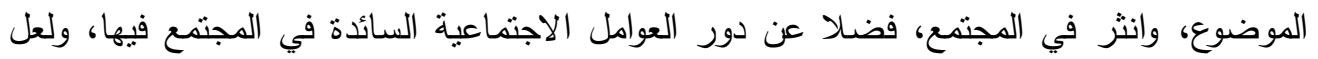

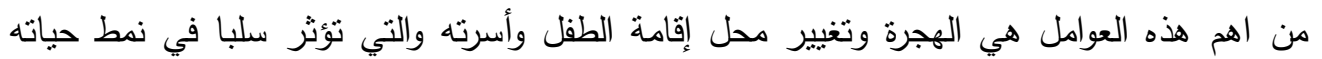
فيعرضه إلى نكسات نفسية وصحية قد تؤدي إلى تهديد حياته ومن ثم الموت.

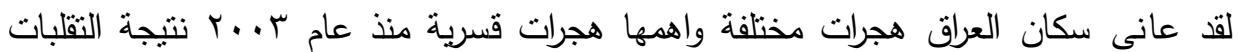
السياسية والأمنية والاجتماعية والاقتصادية والثقافية التي الدت بالبلد، وأخرها سقوط المدن العراقية بيد

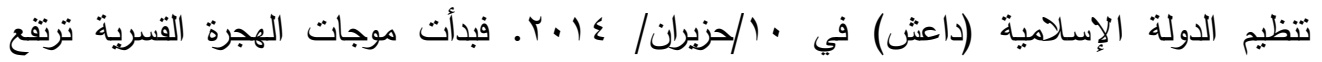
مؤشراتها بين سكان المدن العراقية الساقطة أما لددن عراقية أكثر أمنا أو لبلدان خارج العراق. مما أثر سلبا على نمط الحباة لسكان العراق فتركهم بيوتهم ونمط حباتهم كان له الأثر السلبي

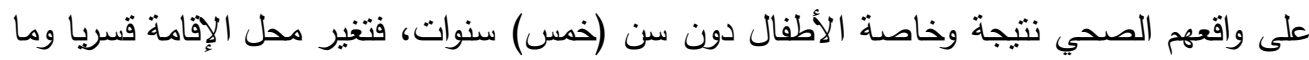

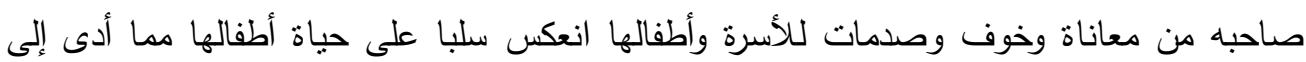
وفيات أطفال الكثير من الأسر المهجرة قسرا. ضمت الدراسة إلى جانب المقمة ثلاثة مباحث، جاء الأول (الإطار المنهجي للاراسة)،

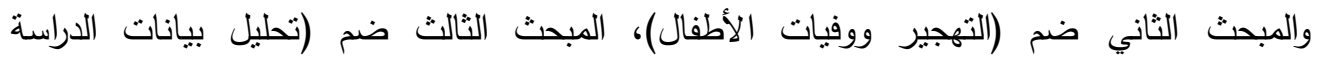

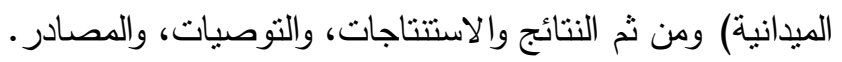
المبحث الأول / الإطار المنهجي للاراسة والأنة

مشكلة الدارة : أن وفيات الأطفال يسأل عنه المجتمع لأنه يتأثر بالظروف والأوضلة الأوضاع السائدة

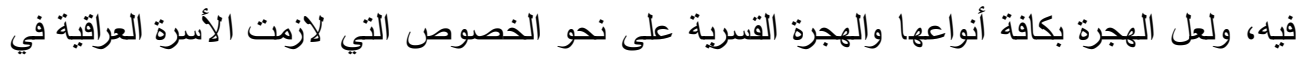

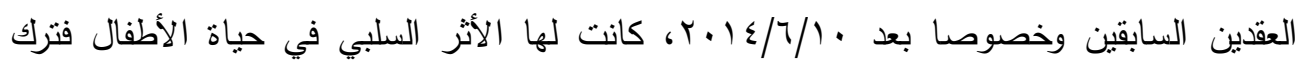

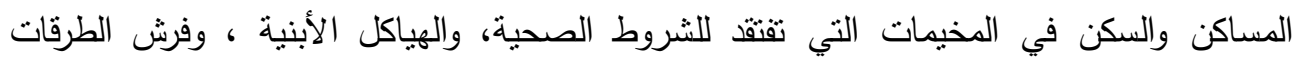

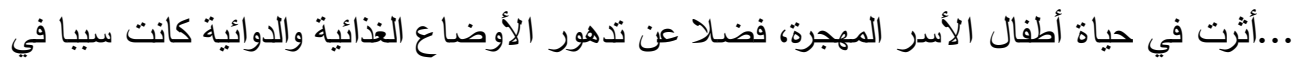

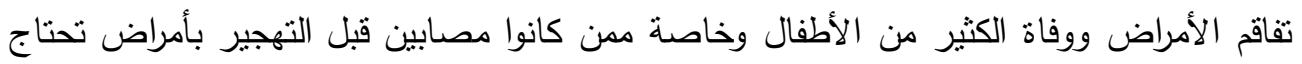
لرعاية صحية وأدوية خاصة ـهذا كله دفع الباحث في التقصي عن وفيات أطفال الأسر العراقية المهجرة إلى إقليم كوردستان العراق منتنكة بمدينة ( أربيل) 
العدد الأربعون

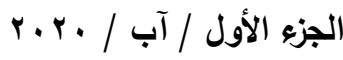

أهداف البحث: لكل بحث هدف أو مجموعة أهداف يسعى الباحث لتحقيقها وبلوغ النتائج العلمية، وأهداف بحثنا تمنلت فيما يأتي:

ا ـ التعرف على نسب وفيات الأطفال الأسر المهجرة في مدينة أربيل. r. الكثف عن الأوضاع الاجتماعية والاقتصادية والصحية للأسر المهجرة التي لها أطفال متوفين. r. ما هي العوامل الاجتماعية والاقتصادية والثقافية المؤدية إلى وفيات الأطفال للأسر المهجرة في مدينة أربيل؟ ع. . توضيح العلاقة بين الهجرة ووفيات الأطفال في مدينة أربيل. ه. التعرف على أسباب وفيات أطفال الأسر المهجرة في مدينة أربيل.

$$
\text { • أهمية البحث: تكمن أهمية البحث في جانبين هما: - }
$$

ا ـ الأهمية العلمية: تعد هذه الدراسة للإجابة على عدة تساؤلات تتاولت موضوع الهجرة القسرية ووفيات الأطفال، كما تحدد أهمية البحث بكونه محاولة للكثف عن وفيات أطفال الأسر المهجرة وطبيعة أثز الهجرة في حدوث الوفيات للأسر المهجرة في العراق بوجه عام ومدينة أربيل على نحو الخصوص، كما إن أهمية هذا البحث تكمن في السعي إلى إضافة دراسة علمية جديدة لتكون مدخلاً لدراسة الهجرة القسرية ووفيات الأطفال ومن أطر متعددة. r ـ الأهمية التطبيقية: يهدف هذا البحث إلى الكثف عن وفيات أطفال الاسر العراقية المهجرة في مدينة اربيل، ودراستها بشكل علمي والوصول إلى تعميمات يمكن من خلالها توضيح الظواهر المماتلة لها في مجتمعنا أو المجتمعات الأخرى.

$$
\text { • مفاهيم البحث: }
$$

ا ـ الوفاة: (الموت) mortality مرفتها منظمة الصحة العالمية ( w.h.o) بأنها الانتهاء التام لجميع مظاهر الحياة، في أي وقت بعد حدوث الولادة الحية، أي توقف الوظائف الحيوية بعد الولادة

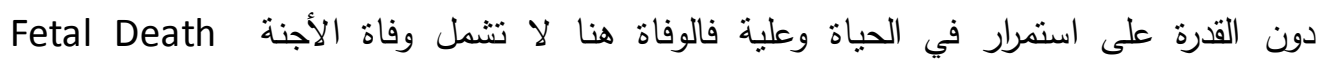
وهذا التعريف هو الذي اعتمد في الدراسة. p;17. Geneva 8to 27 may .O.H.W) r. الطقل: Child عرفته المادة الأولى من مشروع اتفاقية حقوق الطفل العالمية بأنه (كل إنسان لم

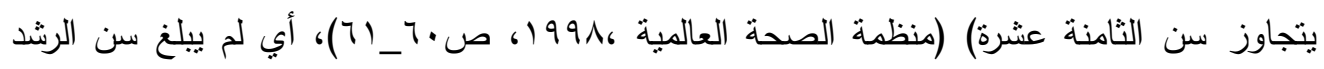
بموجب القانون المنطبق عليه (منظمة الأمم المتحدة للطفولة، .99 199، صع). والطفولة كمفهوم أصبحت تعنى في أدبيات العلوم الاجتماعية نلك الفئة العمرية التي تمند من سن الولادة إلى الثانية 
العدد الأربعون

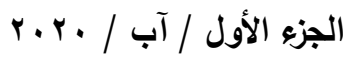

عشرة تقريبا وفي داخل هذه الفئة العمرية هناك تقسيمات فرعية أخرى يمكن إجمالها في مراحل عمرية ثلاث هي بـ(الطفولة المبكرة) وتمثد من الولادة إلى دون الثالثة من العمر ، و (الطفولة الوسطى ) وتمتن من الثالثة إلى دون السادسة من العمر ، و ( الطفولة المتأخرة ) وتمتد من السادسة إلى الثانية

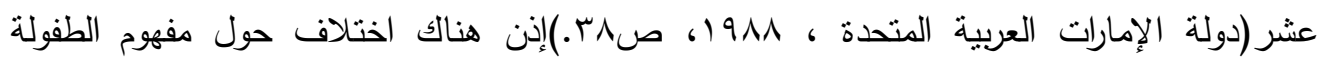
ومراحلها العمرية وعلى نهج ذلك حدنا في الدراسة (الطفل بأنه كل إنسان لم يبلغ سن الخامسة عشر من العمر)، ذلك أن مجتمعنا تحكمه عادات وتقاليد وأعراف تختلف عن يره من المجتمعات، إذ أن ظاهرة الزواج المبكر وخصوصا في المناطق الريفية تحث فيها زيجات في هذا العمر تقريبا فضلا عن أن سن العمل يبدأ من (الخامسة عشر) بحسب القانون التجاري العراقي، وحسب تقديرنا فهو بداية النضج والإدراك وإمكانية الحصول على الدخل المستقل. r. الأسرة: الوحدة الاجتماعية الأولى التي تهدف إلى المحافظة على النوع الإنساني وتقوم على المقتضيات التي يقتضيه العقل الجمعي والقواعد التي نقررها المجتمعات المختلفة ويعدّ نظام

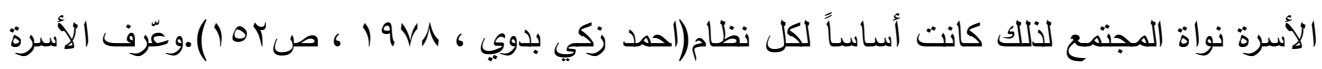

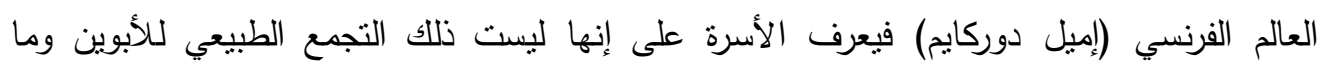
ينجبانه من أولاد على ما يسود الاعتقاد بل إنها مؤسسة اجتماعية تكونت لأسباب اجتماعية ويرتبط

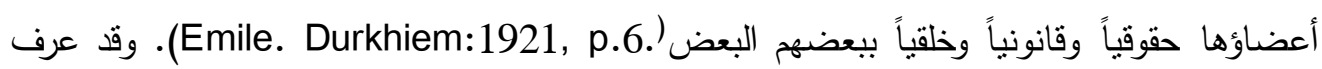
الأسرة العالمان (اوكبرن وينمكوف) في كتابهما الموسوم "علم الاجتماع" على إنها عبارة عن منظمة دائمية نسبياً إذ إنها نتكون من الزوج والزوجة والأطفال أو من دون وجود الأطفال الذين يعيشون في بيت واحد. وتعريفنا الاجرائي للأسرة ما يأني: هي جماعة اجنماعية منتظمة نتكون من الزوج والزوجة ولزية والأبناء غير المتزوجين وقد تتضمن أفراد آخرين كالأبناء المتزوجين وزوجاتهم وأولادهم وبعض هن الأفارب كالجد والجدة والعم والخال... وتربط بينهم علاقات مستمرة ودائمية نسبياً محكومة بمعابير وقيم وعادات اجتماعية متعارف عليها. ع ـ الهجرة: اعرفت منظمة الأمح المتحدة الهجرة بأنها الحركة الجغرافية للأشخاص بين

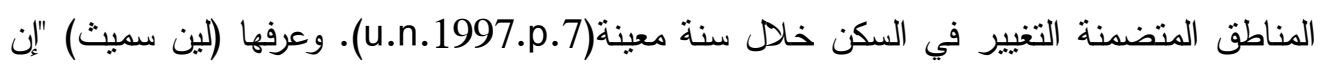
الهجرة هي جميع التحركات المكانية للسكان وما يترتب عليها من تغير مكان الإقامة أو السكن بقصد

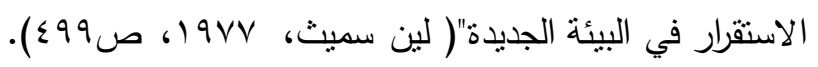

والهجرة السكانية هي انتقال أو ترحال الناس من بلدهم أو موطنهم إلى بلد آخر أو منطقة أخرى، وتحدث الهجرة عادة بسبب كوارث طبيعية أو حروب أو تهجير من قوى غازية أو طلبا للعمل والتمتع 
العدد الأريعون

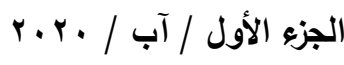

بمستوى معاشي أفضل، وعرفت الهجرة السكانية بأنها التغير الدائم لككان الإقامة من بيئة إلى بيئة

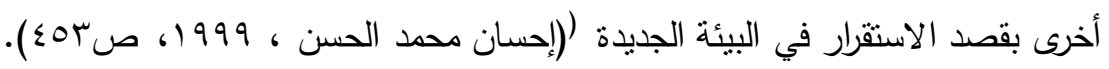

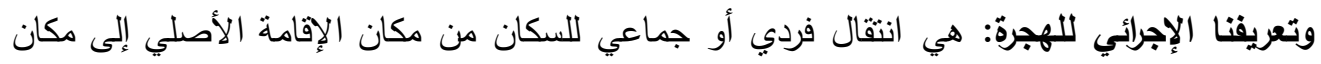

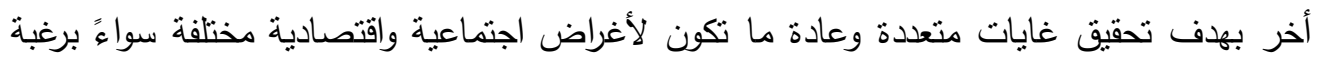
الفرد أو إجبارا.

\section{• منهج البحث}

في محاولة بحث الظاهرة بشكل موضوعي وعلمي استخدم الباحث منهج المسح الاجتماعي الذي

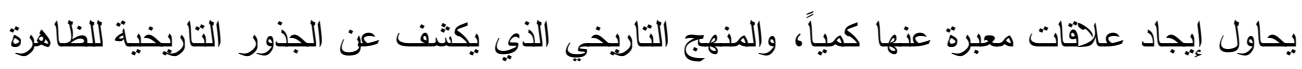
قيد الدراسة.

\section{• عينة البحث}

اختار الباحث عينة تألفت من (r T ) أسرة لها طفل منوفي أثناء التهجير، وبالطريقة العشوائية

$$
\text { • فرضيات البحث }
$$

من اهم مراحل البحث العلمي وضع الفرضيات وتصميمها، لتكون جاهزة للعرض والتحليل للتأكد من صحتها، وتكمن فرضيات دراستتا في: الفرضية الرئيسة: (إن هجرة الأسرة وتغير مكان إقامتها كانت سببا في وفيات الأطفال). • الفرضيات الفرعية

1. أثرت الهجرة على صحة الأطفال مما أدى إلى أصابتهم بالأمراض وثم الوفاة. r r. اكاك علاقة بين الواقع السكني للأسرة ووفيات أطفالها. r. ـ هناك علاقة بين المستوى الاقتصادي للأسرة المهاجرة ووفيات الأطفال

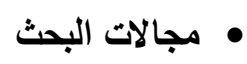

ا ب المجال المكاني / تعد مدينة أربيل مجالا مكانيا للاراسة.

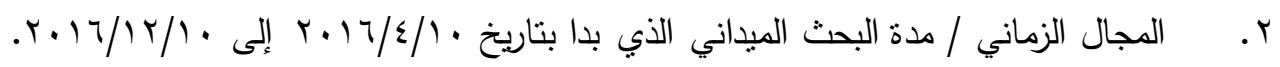
r. الدجال البشري/ الأسر المهجرة التي لها طفل متوفي وتعيش في مدينة أربيل. • - مأدوات الدراسة

أستخدم الباحث في عملية جمع البيانات والمعلومات الخاصة بموضوع الدراسة الوسائل

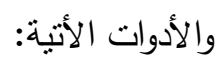


العدد الأربعون

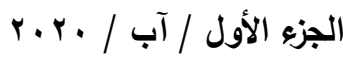

أ. المقابلة: إن المقابلة (Interviem) بمعناها العلمي أي الاتصال الشخصي المنظم والتفاعل اللفظي المباشر الذي يقوم به فرد مع فرد آخر أو أفراد آخرين هدفه استثارة أنواع معينة من المعلومات والبيانات لاستثمارها في البحث العلمي أو للاستعانة بها في التوجيه والتشخيص والعلاج والتخطيط والتقويم في مجتمع الدراسة. والمقابلة تعرف على أنها محادثة تجري بين القائم بالمقابلة وبين فرد أو مجموعة أفراد للحصول على بيانات مهمة لتوظيفها في البحث العلمي(إحسان محمد الحسن ، وعبد

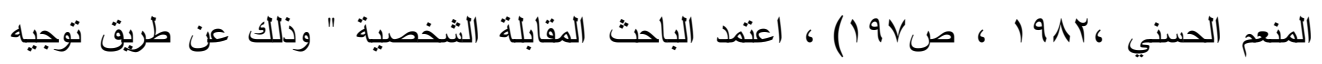
الأسئلة للأسر المبحوثة، ومن ثم تسجيل الإجابة في المكان المخصص لكل منها ". الاستبيان: يعرف الاستبيان بأنه " أداة للبحث نتكون من مجموعة أسئلة يتم صياغتها من قبل الباحثان للحصول على إجابات علمية لتحقيق أهداف يحددها الباحثان في دراسته "( محمد علي محمد ، ب191 ، ، صوسب). وظف الباحث أداة الاستبيان، الذي ضم قسمين من المعلومات، القسم الأول: يحتوي على البيانات الأساسية عن العينة. أما القسم الثاني: يحتوي على وفيات الأطفال للاسر المهجرة يتضمن فقرات جوهربة عن الموضوع، من أجل تحقيق الأهداف المرجوة من الدراسة. خطوات إعداد فقرات الاستبيان

لإعداد استبيان نهائي يقيس موضوع البحث اتبع الباحثان الإجراءات الأثية:

1. استبيان استطلاعي

بعد الاطلاع على أدبيات علم الاجتماع وأدبيات علم اجتماع السكان نم صياغة وإعداد استبيان استطلاعي يضم توضيحاً عن الدراسة من حيث (عنوانها، وكيفية إجابة المبحوثين على فقرات الاستبيان)، وقد تمت صياغة فقرات الاستبيان بصيغتها الأولية منضمنة (ع) فقرة تمثل وفيات أطفال الأسر المهجرة، معتمداً على الأسس العلمية واللغوية الاقيقة في صياغتها.

Validity صدق الاستبيان

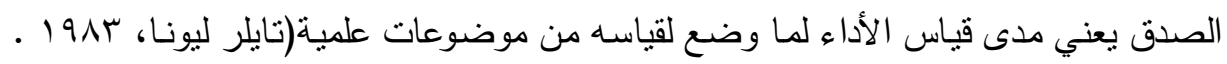
ص صه) ، ويعد الاستبيان صسادقاً ظاهرياً إذا كان يبدو صالحاً في ظاهره وبصورة مبدئيـة من خلال

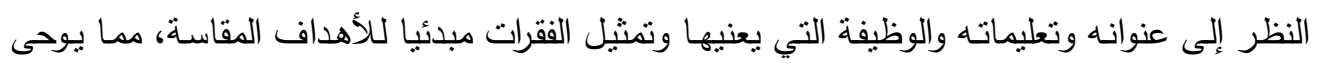
بان الاستبيان من حيث ظاهره انه يناسب إلى حد ما الغرض المطلوب قياسـه(عزيز سمارة ، وآخرون ، 19 ، ، ص • 11 ) ) . لقد تحقق الباحث من صدق الاستبيان باستخدام أسلوب الصدق الظـاهري حيث عرضا فقرات الاستبيان على مجموعة من الخبراء والمختصين بالعلوم الاجتماعية، لغرض بيان آرائهم العلمية في مدى صلاحية الاستبيان للدراسة، وهذا بدل على (الصدق الظاهري) للأداة. 


\section{r. ثبات الاستبيان: Reliability}

يعرف الثبات بأنه " عملية اختبار في نوزيع عدد محدد من الاستبيان على مجموعة من الأفراد

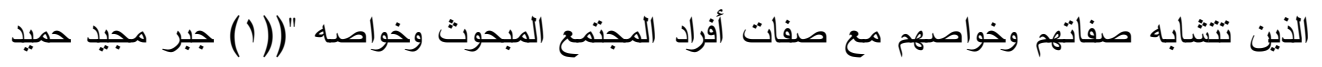

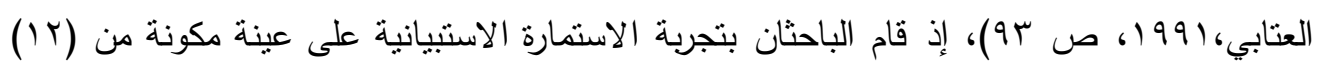

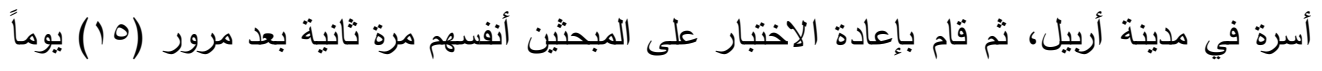

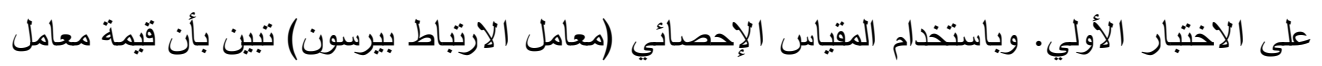

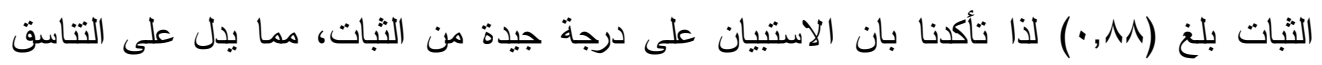
والانسجام في أسئلة استبيانيه. الوسائل الإحصائية

لتحليل البيانات الإحصائية أستخدم الباحثان العديد من الوسائل الإحصائية هي: -

$$
\begin{aligned}
& \text { 1. النسبة المئوية } \\
& \text { r . الوسط الحسابي. } \\
& \text { r. ب. الانحراف المعياري. } \\
& \text { ـ. ـ معامل ارتباط بيرسون }
\end{aligned}
$$

\section{المبحث الثاني}

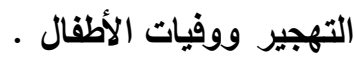

الحديث عن وفيات الأطفال امر في غاية الأهمية من خلال الكثف عن المسببات والأبعاد

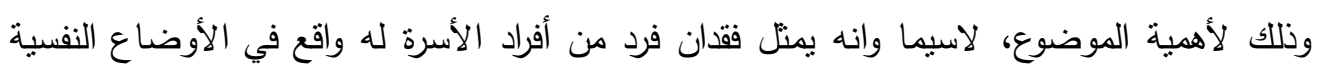

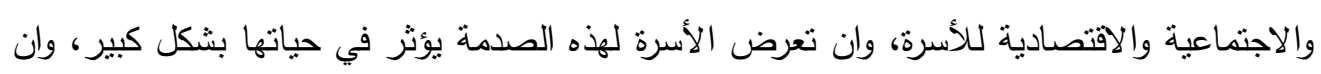

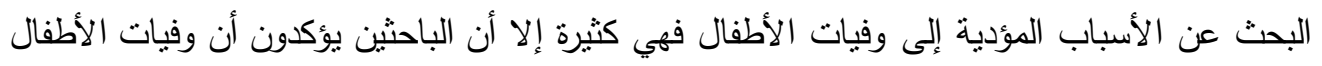

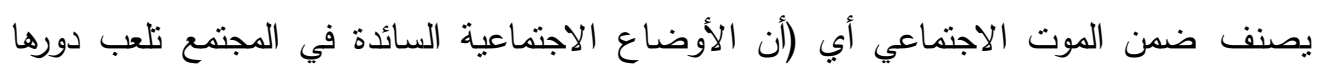

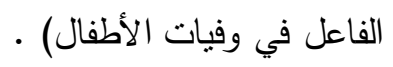
ومن اهم العوامل التي لا تخلو من أثنار في وفيات الأطفال هو تغيير محل الإقامة فالعلاقة واضحة

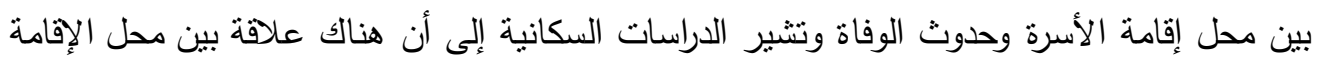

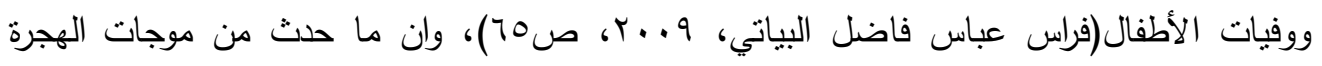
وخاصة الهجرة القسرية لسكان المجتمع العراقي في العقد المنصرم والى يومنا هذا كان لو الوقع في ماتي 
العدد الأربعون

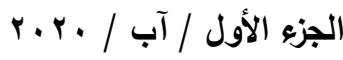

المؤشرات الحيوية لسكان العراق ( الولادات ، والوفيات) ، فالتهجير القسري للأسر العراقية وترك محل الإقامة التي خططت لها ووفرت فيها كافة شروط السكن المثالي المتمثلة بالشروط ( الصحية ) التي تحمي أفرادها من البرد والحر ، والأمراض ، والانتقال إلى المخيمات أو المباني غير المؤهلة للسكن كان له الأثر في الواقع الصحي لسكان العراق وخاصة الأطفال ، ناهيك عن أسلوب التهجير الذي صاحبه الخوف والقلق والانهيار العصبي له الأثر في حياة الأسرة وخاصة الأطفال ، وتشير الدراسات والإحصاءات حول النازحين العراقيين إلى أن غالبية النازحين أصيبوا بالأمراض النفسية نتيجة فقدان

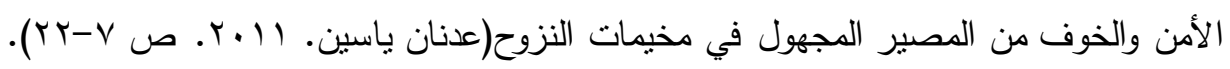
ويرى الباحث أن الكثير من الأسر التي هاجرت أو نزحت عانت الأمرين بسبب الإهمال ونقص الجهود المبذولة لرعايتهم من قبل الجهات المختصة، لاسيما الأسر التي لها أطفال مرضى أو في سن الرضاعة فهي تحتاج إلى أجواء مناسبة لتنشئتهم وتحتاج إلى الظروف المناسبة لسد حاجاتهم من (الحليب، والدواء، والحفاظات)، بل وان بعض الأسر توفي أطفالها أثتاء التهجير والبعض الأخر لم

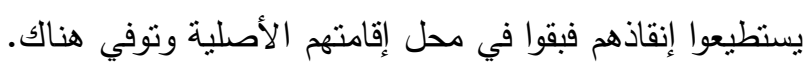
فتشير الدراسات إلى أهمية العوامل الاجتماعية في تغيير محل الإقامة والنزوح، فالاستقرار الاجتماعي، وتحقيق الأمن الاجتماعي يعدان من اهم العوامل المؤثزة في استقرار السكان، وان أي خلل في هذه المنظومة ستؤدي إلى انعدام مقومات الأمن الاجتماعي في المجتمع وبالتالي تتهدد المصالح لاجتماعية لسكان المجتمع منل (العادات، والتقاليد، والأعراف، والممارسات الدينية والعرقية، والحرية ، والتفاعل الاجتماعي ... وغيرها) فيضطر الفرد إلى اللجوء إلى النزوح وتغيير محل الإقامة

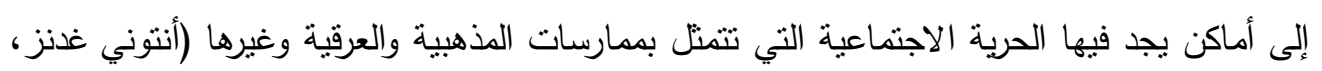

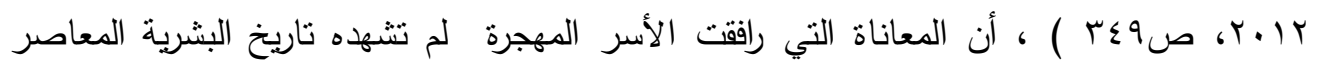
فموجات الهجرة التي عصفت بالأسر العراقية أثرت سلبا في نمط حياتها وأسلوب العيش مما اثر سلبا في أمد الحياة فيها ، والإصابة بالأمراض ، ومن ثم حدوث الوفيات .

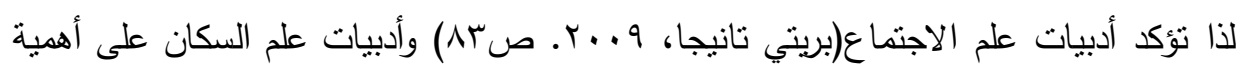
محل الإقامة من جهة وتأكيدها على الدور المؤثر للهجرة القسرية الناتجة عن سوء الأحوال الأمنية وانتشار القتل الطائفي وغيره في حياة السكان المهجرين وخاصة إذا ما كانت الهجرة مجهولة الجهة والمصير ، ويرى الباحث أن الأسر المهجرة قسرا من مدنها عانت الأمرين ويمكن الإشارة إلى بعضها فيما بأني: 
العدد الأربعون

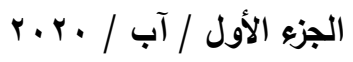

ا. فقدانها لكل شيء المسكن والأغراض المنزلية، والبعض منها فقدانها لأبنائها أو بناتها فكانت الصدمة مؤثرة جدا.

r. الانهيار النفسي للأسرة وأفرادها، وانتشار الأمراض والأزمات بين أفرادها.

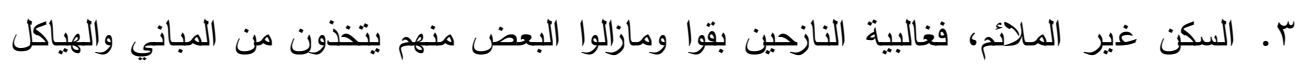
مكانا للعيش. ـ. أن المجرين الذين يسكنون المخيمات يعانون من نقص حاد في جوانب الحياة الأساسية

$$
\text { (الغذاء، الدواء، الملبس، والفراش....). }
$$

ه. انتشار البطالة وانهيار الوضع الاقتصادي للكثير من الأسر المجرة اثر ذلك على سد حاجاتها

$$
\text { من الدواء والغذاء. }
$$

لعل هذه الأسباب وفقدان الرعاية الحكومية المناسبة لهم لانشغال الحكومة بالحرب ، وانتشار الفساد

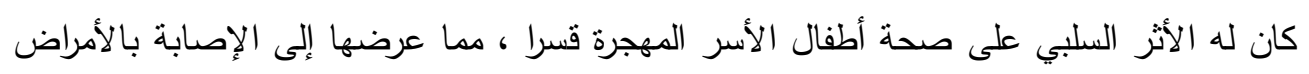

$$
\text { وتهديد حياتهم ومن ثم الوفاة . }
$$

ويمكن أن نعبر عن ابعاد الهجرة القسرية في وفيات الأطفال في المخطط الاتي .

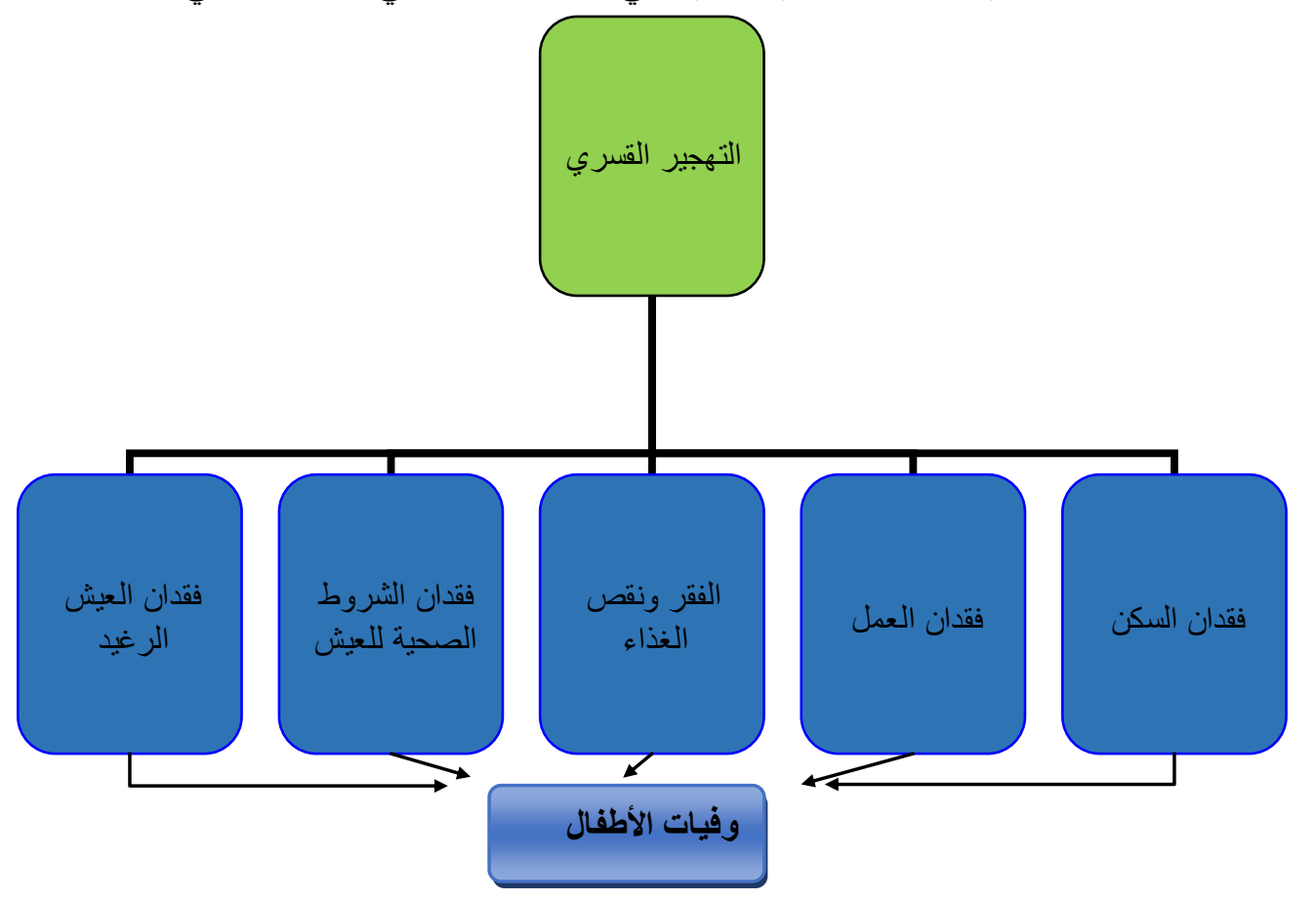




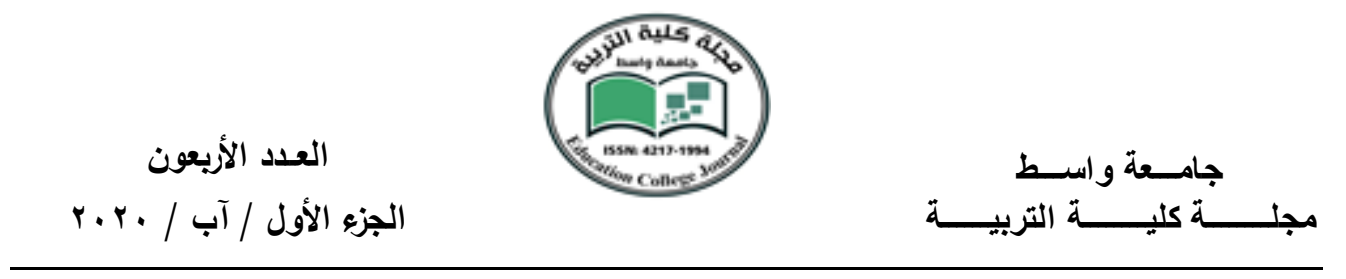

المبحث الثالث

تحليل بيانات الداسة الميدانية.

أولاً: البيانات الديموغرافية

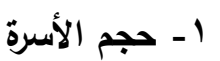

من اجل بلوغ النتائج الإحصائية الدقيقة قسمنا اسر العينة من حيث الحجم إلى اسر صغيرة

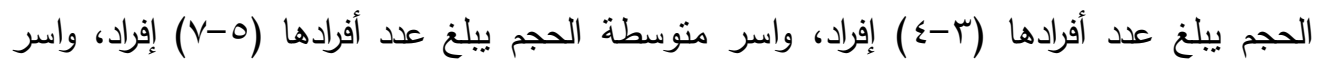

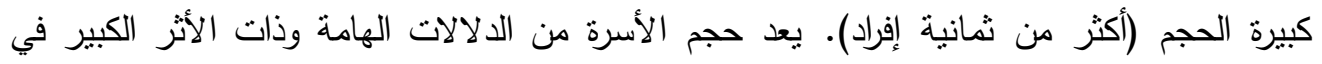

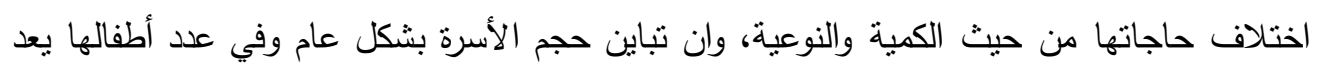
مؤشرا هاما على اختلاف حجم الاستهلاك.

\begin{tabular}{|c|c|c|}
\hline$\%$ & العدد & حجم لأسرة \\
\hline$r V_{6} V$ & $\sum 7$ & صغيرة الحجم \\
\hline$\sum 9, r$ & 7. & متوسطة الحجم \\
\hline$\left|r_{6}\right|$ & 17 & كبيرة الحجم \\
\hline $1 \ldots$ & Kr & المجموع \\
\hline
\end{tabular}

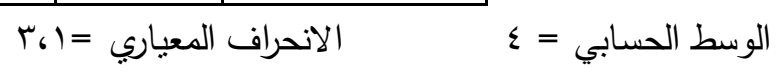

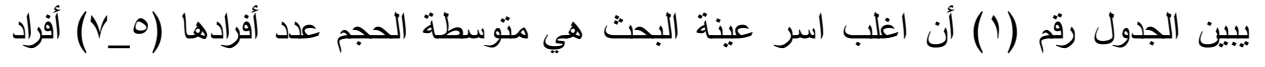

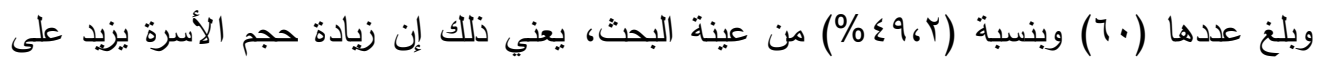

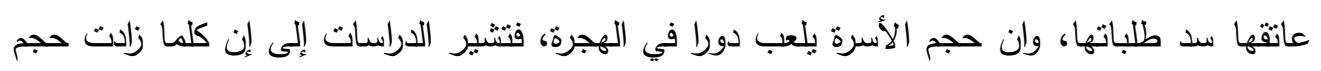

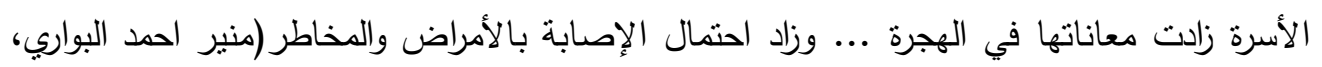

الجدول رقم (ץ) يبين حجم الأسرة ودخلها الشهري

\begin{tabular}{|c|c|c|}
\hline$\%$ & 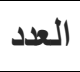 & الاخل الثهري بالألف \\
\hline$\varepsilon 9, r$ & 7. & $\leqslant q q-r \ldots$ \\
\hline$r \leq 67$ & r. & $\vee q 9 \_0 \ldots$ \\
\hline
\end{tabular}


العدد الأربعون

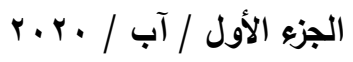

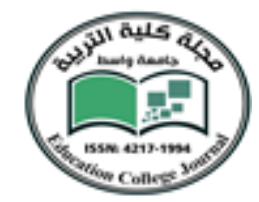

\begin{tabular}{|c|c|c|}
\hline $1 \varepsilon_{6} 1$ & 11 & $999-\wedge \ldots$ \\
\hline $11 ، \varepsilon$ & $1 \varepsilon$ & $1 r q q-11 \ldots$ \\
\hline $1 \ldots$ & Mr & المجموع \\
\hline
\end{tabular}

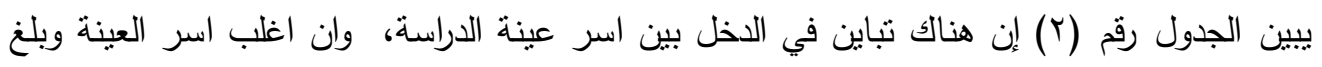

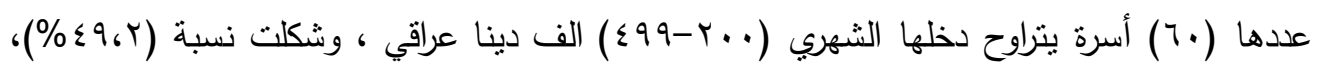

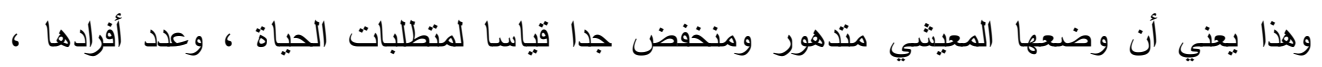

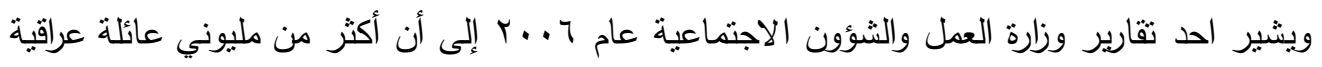

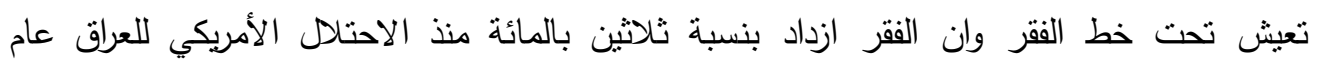

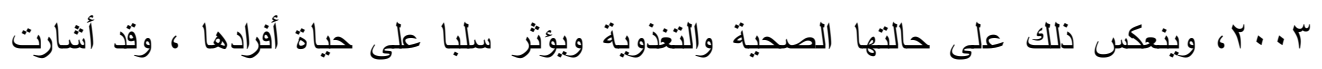

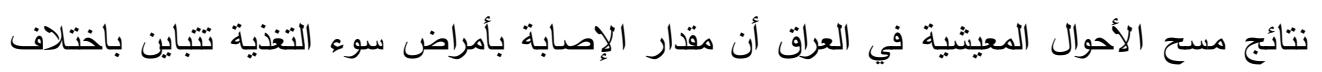

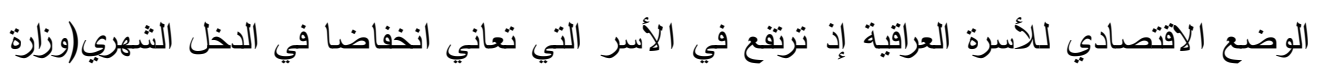

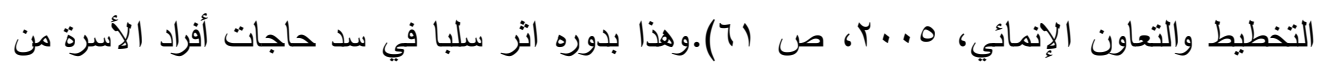

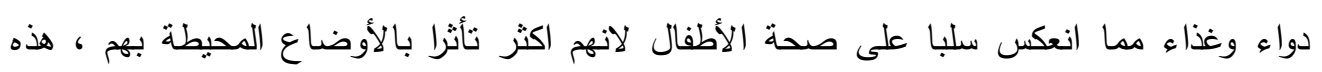
النتيجة تحقق الفرضية ( هناك علاقة بين المستوى الاقتصادي للأسرة المهجرة ووفيات الأطفال ) . r- مهنة رب الأسرة

إن للمهنة الني يزاولها الإنسان إثر على طبيعة حياته وأسلوب عيشه ومن ثم حياة أسرته، وتعد

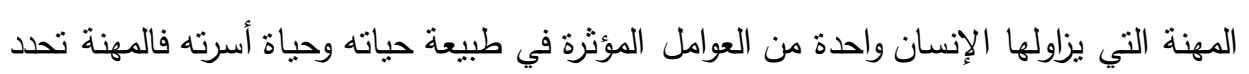

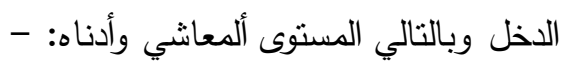

الجدول رقم (ץ) يبين مهن الوالدين في عينة الدراسة

\begin{tabular}{|c|c|c|c|c|}
\hline \multicolumn{2}{|c|}{ نوع المهنة \% } & \multirow[t]{2}{*}{$\%$} & \multirow[t]{2}{*}{ العدد } & \multirow[t]{2}{*}{ المهنة } \\
\hline حرة & وظيفية & & & \\
\hline$\{, 4$ & $\Delta ৭, \xi$ & 14,9 & iv & يعمل \\
\hline--- & --- & 14.1 & 1.0 & لا يعمل \\
\hline--- & --- & $1 \ldots$ & IYY & المجموع \\
\hline
\end{tabular}


العدد الأريعون

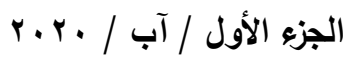

يتضح من الجدول رقم (r) أن اغلب الأسر الني حدثت فيها حالات وفيات الأطفال من عينة

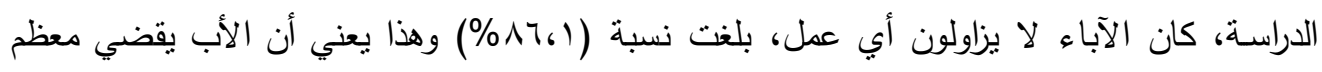

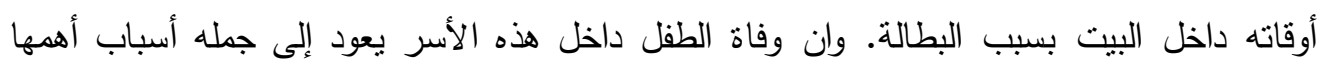
القصور المادي للأسرة وانخفاض وعي الأسرة وخاصة الأم في الجوانب الصحية والتغذية.

\section{ع - نوع السكن بعد الهجرة}

يعد السكن من اهم الحاجات الأساسية بعد الغذاء للإنسان، وان المسكن هو أحد اهم مقومات الأمن

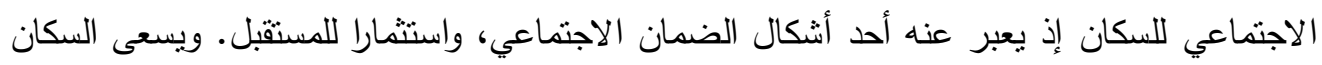

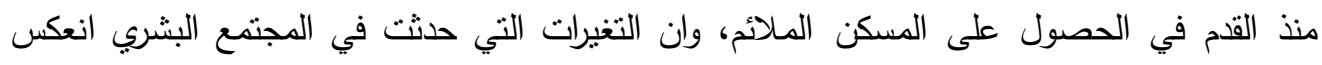
على الواقع السكني من حيث التصميم والتأثيث (الديكور) وهذا أيضا فتح بابا جديدا للاستهلالك. الجدول رقم (؛) يبين نوع وعائديه المسكن

\begin{tabular}{|c|c|c|}
\hline$\%$ & العدد الع & نوع المسكن \\
\hline $0 \leqslant, 1$ & 74 & مخيم \\
\hline r & $\varepsilon r$ & منزل إيجار \\
\hline 11.0 & $1 \varepsilon$ & هيكل حكومي وغيره \\
\hline $1 \ldots$ & IYY & مجموع \\
\hline
\end{tabular}

يبين الجدول رقم (ع) إن أعلى نسبة وهي (1، (ه\%) من عينة البحث اتخذت من المخيمات سكنا

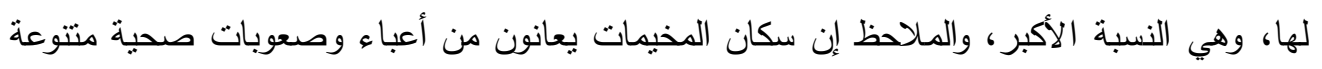
منها: 1. انتشار الأوبئة والأمراض نتيجة عدم توفر الثروط الصحية في هذه المخيمات. r. الإهمال الصحي من قبل الجهات المختصة، وعدم توفر المستلزمات الصحية المتمثلة بالمراكز

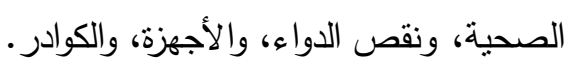
r. فقدان شروط السلامة الصحية نتيجة الاكتظاظ السكاني في هذه المخيمات. وهنا تحققت الفرضية الموسومة (هناك علاقة بين الواقع السكني للأسرة المهرة ووفيات أطفالها). 
العدد الأربعون

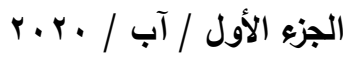

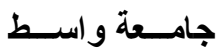

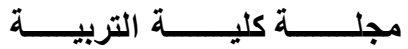

0- الخلفية الاجتماعية

الجدول رقم (•) يبين الخلفية الاجتماعية للعينة

\begin{tabular}{|c|c|c|}
\hline$\%$ & العدد & الخلفية الاجتماعية \\
\hline$\sum r_{6} T_{1}$ & or & ريفية \\
\hline ovgr & $v$. & حضرية \\
\hline $1 \ldots$ & IKr & المجموع \\
\hline
\end{tabular}

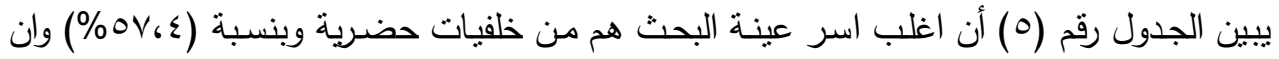

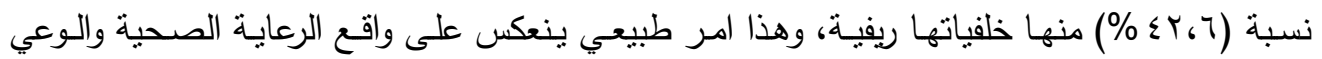

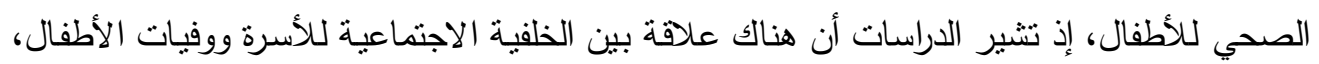

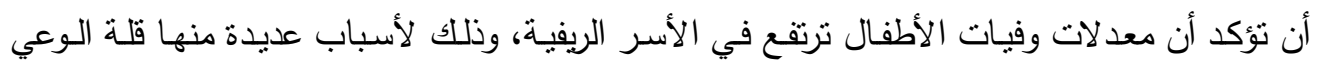
الصحي والثقافي للأسرة. وعلى الرغم من أن نسبة الأسر الحضرية اعلى من الريفية إلا أن الهجرة والتهجير أثرا على طبيعة الحياة الأسرية وبعض السلوك الصحي للأسرة. ؟- المستوى التعليمي للأبوين أثارت الدراسات الإنسانية لاسيما الاجتماعية والصحية والطبية منها إلى أن كل سنة إضافية

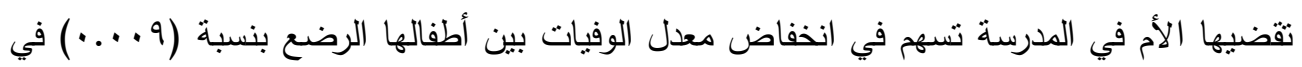

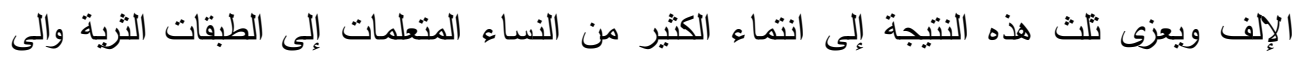

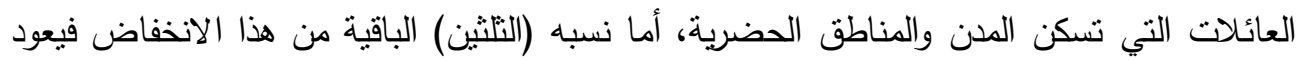

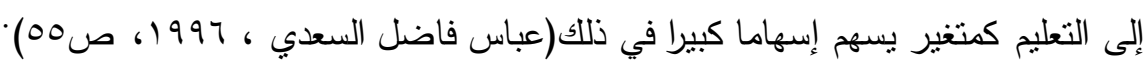
الجدول رقم (؟) الذي يبين التحصيل الدراسي للوالدين.

\begin{tabular}{|c|c|c|c|c|}
\hline$\%$ & الأم & $\%$ & الأب & التحصيل الدراسي \\
\hline 0.61 & TY & $\varepsilon \varepsilon_{6} r$ & $0 \leqslant$ & أمى \\
\hline 11 & rt & YT. T & rt & يقرا ويكتب \\
\hline 1968 & r. & $1 \varepsilon_{6} \wedge$ & 11 & ثانوية (متوسطة وإعدادية) \\
\hline $1.6 \mathrm{~V}$ & ir & $1 \pi .9$ & iv & جامعية فأكثر \\
\hline $1 \ldots$ & IYY & $1 \ldots$ & IrY & المجموع \\
\hline
\end{tabular}


العدد الأريعون

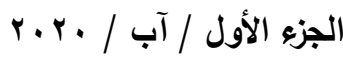

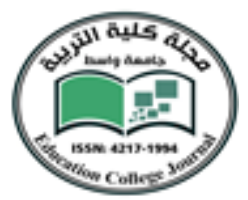

يتضح من الجدول رقم (7) أن معظم الوالدين في اسر العينة كانوا (أميين) إذ بلغت نسبه

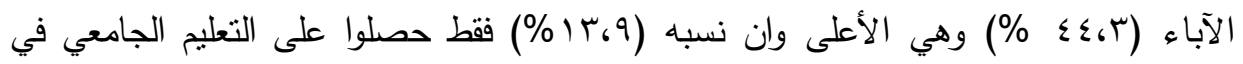

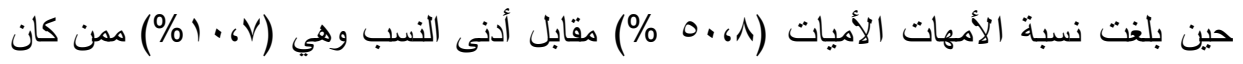

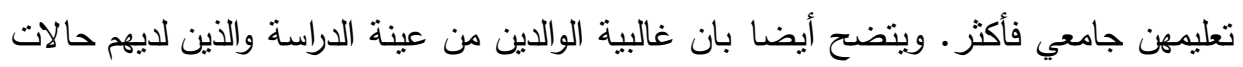

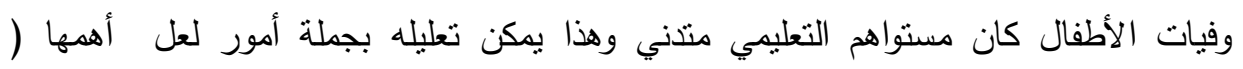

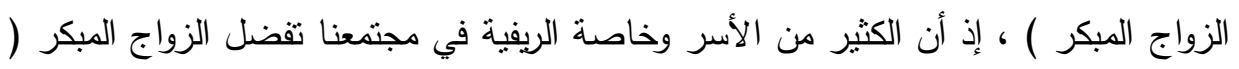

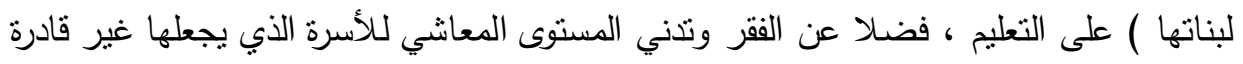

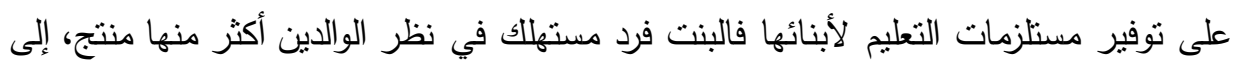

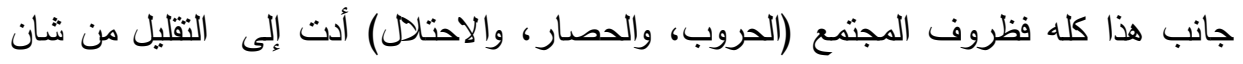

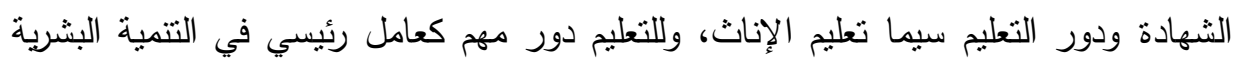

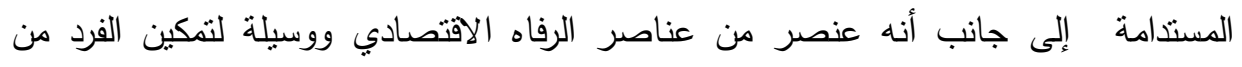

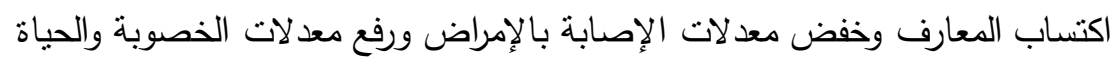

ثانيا: البيانات الاجتماعية عن الطقل المتوفي V - عمر الطفل المتوفي وجنسه

يميل معدل حياة الأطفال إلى ارتفاع تبعا لعوامل عديدة منها ما يتعلق بالظروف المحيطة بها، ومنها

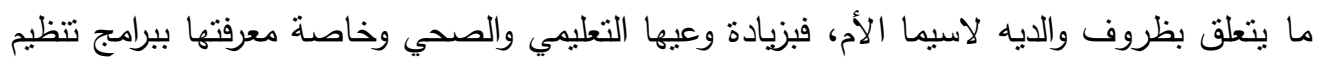

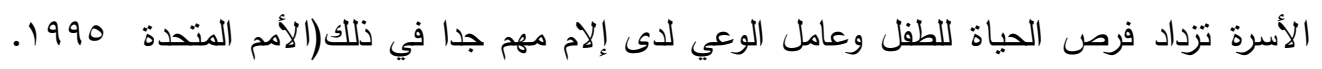

الجدول رقم (V) يبين نسب وفيات الأطفال بحسب العمر والجنس

\begin{tabular}{|c|c|c|c|c|c|c|}
\hline$\%$ & الإناث & $\%$ & الذكور & $\%$ & عدد الأطفال المتوفين & عمر الطقل بالسنة \\
\hline$\checkmark \wedge, 7$ & ro & M. & 17 & $\varepsilon 1,1$ & 01 & دون السنة \\
\hline 79.6 & rt & $r \cdot r r$ & 1. & rV & rt & دون الخامسة \\
\hline$V \cdot ، \Lambda$ & IV & r9, & $v$ & 19.7 & $r \varepsilon$ & دون العاشرة \\
\hline$r \Lambda_{6} \wedge$ & $\varepsilon$ & VI. & 1. & 11,0 & $1 \varepsilon$ & 11 - دون ه اسنة \\
\hline$\% 74$ \% & vq & \%ro، & $\varepsilon r$ & $1 \ldots$ & Irr & المجموع \\
\hline
\end{tabular}


العدد الأريعون

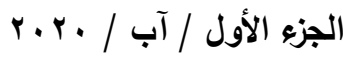

يتضح من بيانات الجدول رقم (V) إن وفيات الأطفال دون سن (السنة) سجلت ما نسبته (^، اء\%)، وهي الأعلى من بين وفيات الفئات العمرية الأخرى، وهذا طبيعي إذ أن الأطفال دون

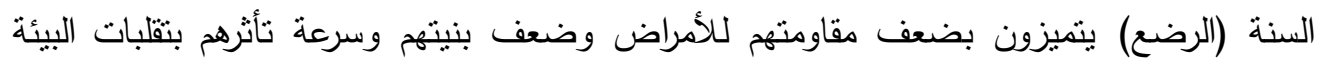

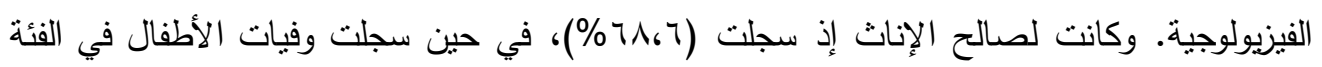

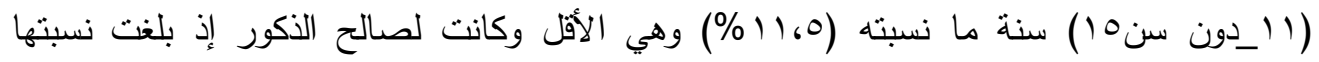

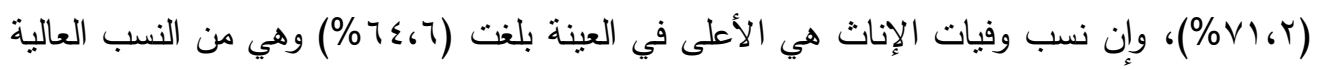

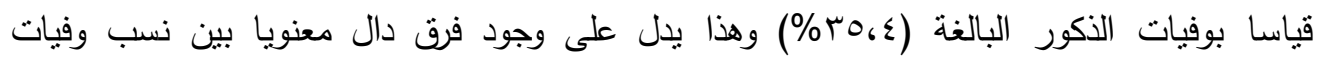

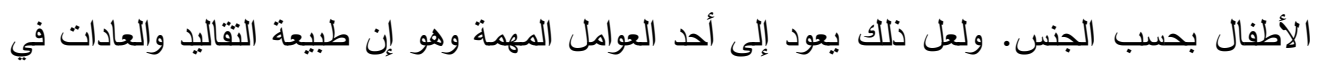

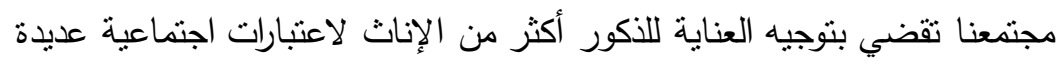

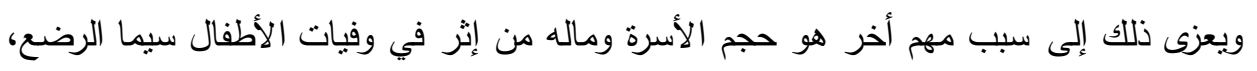
فكبر حجم اسر بعض الأطفال في عينة الدراسة يؤثر سلبا في قدرة الأسر على إعالة وتنتئة أطفالها

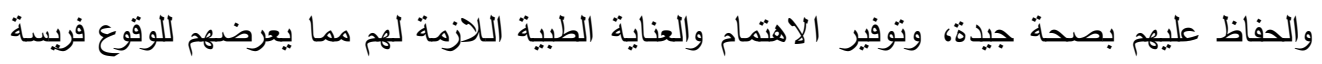

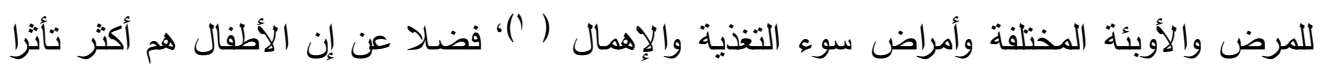

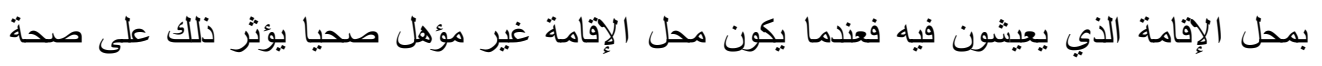

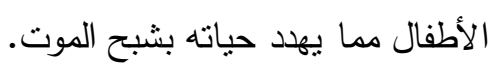
هنا تحققت الفرضية الموسومة (أثرت الهجرة على صحة الأطفال مما أدى إلى أصابتهم

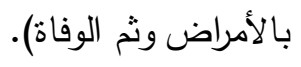

^- - مكان حدوث الوفاة

الجدول رقم (^) ييين مكان حدث الوفاة

\begin{tabular}{|c|c|c|}
\hline$\%$ & العدد العد & الإجابات \\
\hline$\Lambda_{6} r$ & 1. & في الطريق أثناء الهجرة \\
\hline$\leqslant 0,9$ & 07 & 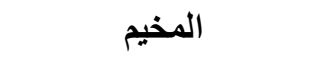 \\
\hline$r$ & $\varepsilon r$ & البيت \\
\hline 111,0 & $1 \leq$ & المستثفى \\
\hline $1 \ldots$ & MY & المجموع \\
\hline
\end{tabular}


العدد الأربعون

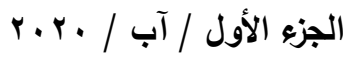

يتضح من الجدول رقم (^) إن أعلى نسب وفيات الأطفال قد حدثت في المخيم الذي يسكنه

غالبية المهجرين ذوي الدخول المنخفضة الذين ليس بإمكانهم دفع الإيجار وبنسبه ( 9،0؛ \%) ويعود ذللك إلى عدم نقل الطفل في حالة مرضه إلى المسنثفى ، إما بسبب جهل الوالدين بكيفية التعامل مع طفلهم وعدم نقله لتلقي الرعاية الصحية والجهل بالطرق اللازمة لحمايته والتعامل مع حالته إثثاء تدهورها صحيا ، أو إلى تدني المستوى الاقتصادي للأسرة مما يجعل منها عاجزة عن توفير الأدوية لطفلها لحين نقله للمستشفى وعرضه على الأطباء المختصين بسبب التكاليف العالية فتقوم الأسرة بعلاجه بالطب الثعبي أو الرقية أي منزليا فضلا عن عدد من الأسباب منها :ا - عدم إبداء الاهتمام الكافي للأطفال بسبب كثرة الظروف التي يعيشون فيها في الهجرة أو بسبب انشغال الوالدين ولاسيما الأم.

r - تدهور الأوضاع الصحية والخدمات الصحية المقدة للمهرين بصورة عامة، والمهجرين الساكنين في المخيمات على نحو الخصوص. r ـ الإيمان البسيط بالقضاء والقدر الذي يترك أحيانا الأمور حتى تتفاقم.

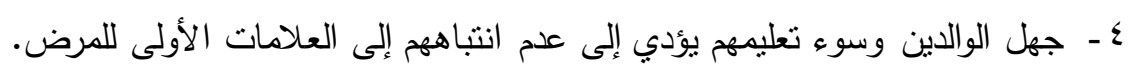

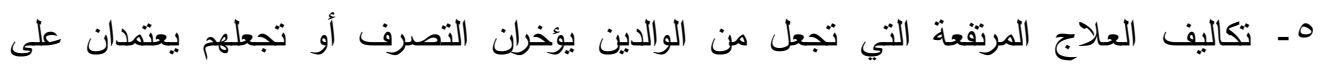
العلاجات المنزلة الرخيصة أو المصنعة محليا، أو الاعتماد على النساء كبيرات السن من العائلة

والجيران.

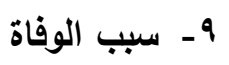

جدول رقم (9) يبين أسباب الوفاة

\begin{tabular}{|c|c|c|}
\hline$\%$ & العدد العد & الأسباب \\
\hline 70,7 & $\wedge$. & 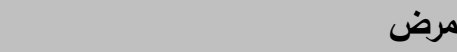 \\
\hline r7, r & rt & التعرض للاغة الحيوانات أو الحشرات \\
\hline$\Lambda_{6} Y^{\prime}$ & 1 . & (اصابة_حادث سبارة) \\
\hline $1 \ldots$ & IrT & المجموع \\
\hline
\end{tabular}

يتضح من الجدول رقم (9) إن أكثر من نصف وفيات الأطفال في عينة الدراسة كانت بأسباب مرضية أي إن الطفل أصيب بإحدى الأمراض ولم ينجو منها، وبلغت نسبة (707\%) من العينة، ويمكن إن نعزو نللك إلى الأسباب التي سبق وان أشرنا اليها في الأسطر والصفحات السابقة التي تتمنل في (عدم الإمكانية الاقتصادية للأسرة في علاج أطفالها، عدم توفر الرعاية الصحية في 
العدد الأربعون

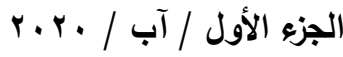

مناطق سكناها انتشار الأوبئة والأمراض في المخيمات السكنية، قلة الوعي الصحي والنقافي للأسرة

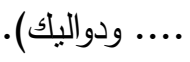

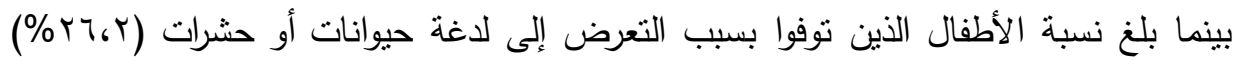
وهي نسبة كبيرة أيضا، هذا ناتج عن أسباب كثيرة أهمها: '. إن غالبية الأسر النازحة تسكن المخيمات وهي مجمعات سكنية غير مؤهلة للسكن البشري لعدم نوفر شروط السلامة الصحية فيها. r. إن غالبية المخيمات تكمن في مناطق جغرافية نائية كانت سابقة أراضي منروكة أو بأطراف

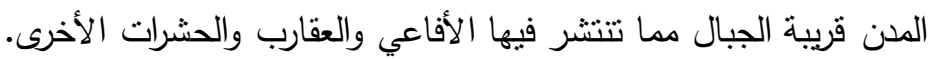
r. إن نسبة كبيرة من الأسرة التي نزحت سكنت بيوتا ومباني غير قابلة للسكن البشري.

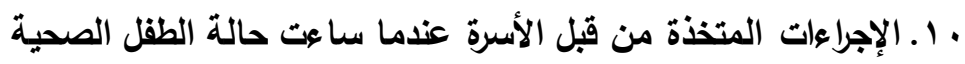

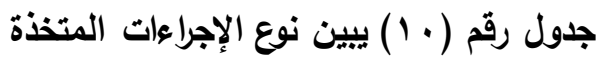

\begin{tabular}{|c|c|c|}
\hline$\%$ & العدد & الإجراءات المتخذة \\
\hline 41.1 & rᄉ & نقل مباشرة إلى المستشفى \\
\hline 11 & rt & نقل بعد فترة إلى المستثفى \\
\hline \& & $0 \leqslant$ & عولج منزليا \\
\hline 7.7 & $\wedge$ & تم أخذه إلى السيد لغرض الرقية \\
\hline $1 \ldots$ & irr & المجموع \\
\hline
\end{tabular}

يتضح من الجدول أعلاه أن أعلى النسب وهي ( r،؛؛\%) من الأطفال عولجوا منزليا أب قام

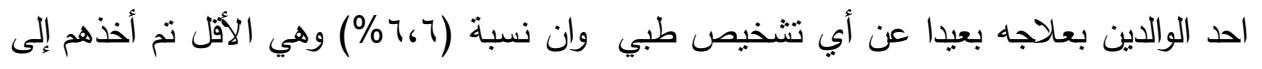

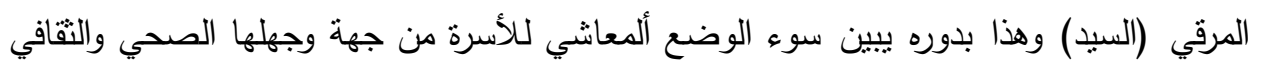

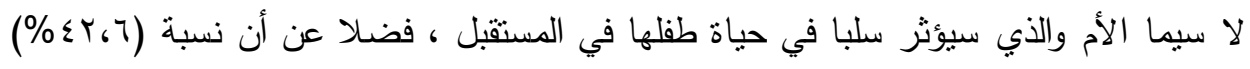

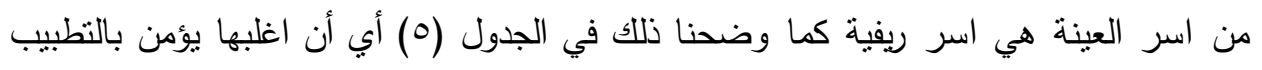

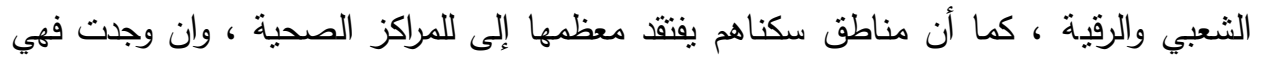
متواضعة في تجهيزاتها وكوادرها . 
العدد الأربعون

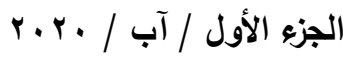

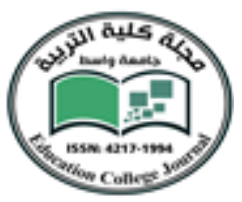

• 1 ـ هل راجعت المستثفى أو المركز الصحي قبل الوفاة

جدول رقم ( • (1) يبين هل إن الأسرة راجعت المستشفى قبل وفاة الطقل

\begin{tabular}{|c|c|c|}
\hline$\%$ & العدد & الإجابات \\
\hline TV & זr & نعم \\
\hline r & 19 & لا \\
\hline $1 \ldots$ & IrT & المجموع \\
\hline
\end{tabular}

يبين الجدول رقم (· (1) إن غالبية اسر العينة لم تراجع المسنشفى قبل وفاة طفلها وبلغ عددها (19) أسرة، وبنسبة (\% \% \%)، هذا مؤشر خطير جدا يوعز لنا أمور عديدة أهمها: ! . إهمال الأسرة للوضع الصحي للطفل وعدم منابعته. r. إن غالبية الأسر تعاني من تدهور المستوى التقافي والصحي وخاصة الزوجين. r. إن الهجرة أثرت على الأوضاع الحياتية للأسرة ومنها الأوضاع المعيشية والثقافية والنفسية ... وغيرها.

بينما يشير الجدول إن (rr) أسرة وبنسبة (rV\%) فقط راجعت المستشفى المراكز الصحية قبل وفاة طفلها. 11 - الماذا لم تراجع المستثفى وهاه جلول رقم (11) يبين أسباب عدم مراجعة الأسرة للمستشفى

\begin{tabular}{|c|c|c|}
\hline التسلسل المرتبي & 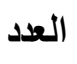 & 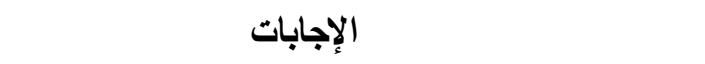 \\
\hline 1 & $\varepsilon$ & عدم وجود مستشفى في المخيم أو منطقة السكن \\
\hline r & 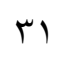 & ليس لاي وساطة نقل للذهاب إلى المستشفى البعيدة \\
\hline r & rt & ليس لاي علم بخطورة حالة الطقل \\
\hline$\varepsilon$ & r & لم أكن في البيت \\
\hline
\end{tabular}

يبين الجدول رقم (11) إن هناك تباينا في إجابات العينة حول أسباب عدم مراجعتهم للمسنشفى قبل وفاة طفلهم، وكانت حسب ما يأني:

أ. جاء السبب (عدم وجود مستثفى في المخيم أو منطقة السكن) في المرتبة الأولى من التسلسل المرتبي لأسباب عدم مراجعة الأسرة للمستشفى قبل وفاة طفلها، وبلغت عدد الإجابات ( •ـ) إجابة. 
العدد الأربعون

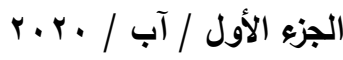

ب. جاء السبب (لبس لدي وساطة نقل للذهاب إلى المسنشفى البعيدة) في المرتبة الثانية من التسلسل المرتبي لأسباب عدم مراجعة الأسرة للمستشفى قبل وفاة طفلها، وبلغت عدد الإجابات (اسب) إجابة. ت. جاء السبب (ليس لدي علم بخطورة حالة الطفل) في المرتبة الثالثة من التسلسل المرنبي لأسباب عدم مراجعة الأسرة للمستشفى قبل وفاة طفلها، وبلغت عدد الإجابات (Yr) إجابة. ث. جاء السبب (لم أكن في البيت) في المرتبة الرابعة والأخيرة من التسلسل المرتبي لأسباب عدم مراجعة الأسرة للمستشفى قبل وفاة طفلها، وبلغت عدد الإجابات (r ا ( إجابة. نرى مما سبق إن الأسباب اختلفت وتتوعت فضلا عما تقدم هناك أسباب أخرى نراها واضحة عند مقابلتتا للاسر تتعلق بالأمور الاقتصادية فغالبية الأسر ذات وضع اقتصادي مندني وحالتها فقيرة جدا، فضلا عن مكان السكن غير المؤهل صحيا وغيرها. r أسباب خروج الطفل من المستثفى الجدول رقم (Y Y) يبين أسباب خروج الطفل المريض من المستشفى.

\begin{tabular}{|c|c|c|}
\hline$\%$ & 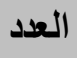 & أسباب الخروج \\
\hline$\left|r_{6}\right|$ & $\varepsilon$ & شفائهـ التام \\
\hline ( & 11 & ارتفاع نفقه العلاج داخل المستشفى \\
\hline m & ir & نقص الأدوية \\
\hline $1 \Lambda_{6} Y$ & 7 & الوفاة \\
\hline $1 \ldots$ & r & المجموع \\
\hline
\end{tabular}

يتضح من الجدول رقم (YM) أن (Tr) طفلا من عينة الدراسة من الذين نقلوا إلى المستشفى توفوا رغم دخولهم لتلقي العلاج، وهذا مؤشر على قصور الخدات الصحية ونقص الأدوية والكوادر وارتفاع نفقات العلاج في المستشفى وهو أحد أسباب الوفاة المتكررة في تلك الحقبة. وتجدر الإشارة إلى أن الصحة العامة في العراق واجهت تحديا خطيرا تمنل بزيادة المخاطر البيئية والافتقار إلى الرعاية الصحية الطبية والخدمية اللازمة، إلى جانب نقص الغذاء والدواء مما انعكس سلبا على سكان العراق ولاسيما فئة الطفولة التي طاردها شبح الموت

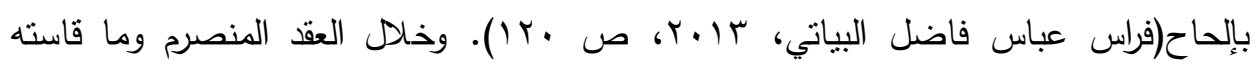
الأسرة العراقية من ظروف صعبه جعلها تعيش أجواء غير مربحة لافتقارها للموارد المالية التي تمكنها من الحصول على الخدات الضرورية ومنها ( الصحية ) والخوف والمرض والإصابة به 
العدد الأربعون

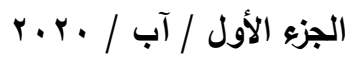

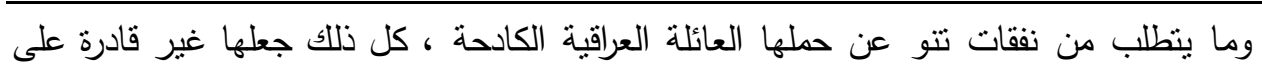

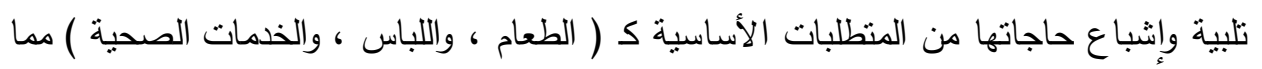

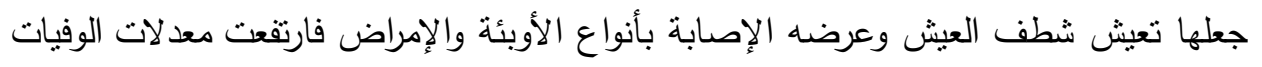

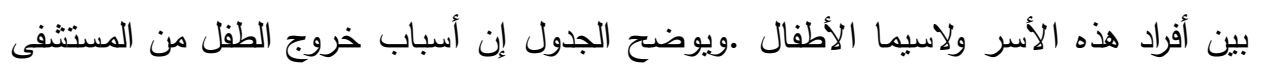

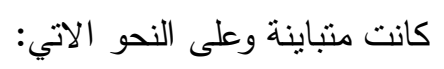

أ.بلغ عدد الأطفال الذين غادروا المستشفى بسبب الثفاء التام (ء) أطفال وبنسبة (1، أ1\%) وهي نسبة قليلة جدا.

ب. بلغ عدد الأطفال الذين غادروا المستشفى بسبب ارتفاع نفقة العلاج داخل المستشفى (1)

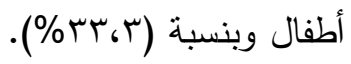

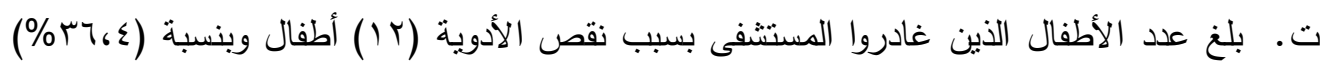

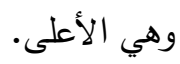
ث. بلغ عدد الأطفال الذين غادروا المستثفى بسبب الوفاة (؟) أطفال وبنسبة (r،11\%) هذا مؤشر على إن دخول الطفل للمستشفى لم يساعد في تحسن حالته الصحية.

r ا 1 -هل راجعت طبيبا مختصا

جدول رقم (r I ) يبين هل إن الأسرة لاجعت طبيبا مختصا

\begin{tabular}{|c|c|c|}
\hline$\%$ & العدد & الإجابات \\
\hline 176.5 & r. & نعم \\
\hline Tr. & $1 . r$ & ע \\
\hline $1 \ldots$ & Irr & المجموع \\
\hline
\end{tabular}

يبين الجدول رقم (r/) إن غالبية الأسر المبحوث لم تراجع طبيبا مختصا عند مرض طفلها وقبل

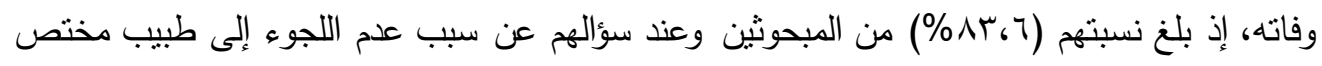

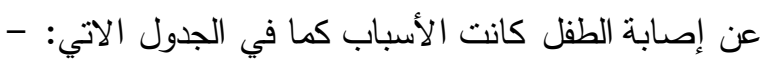

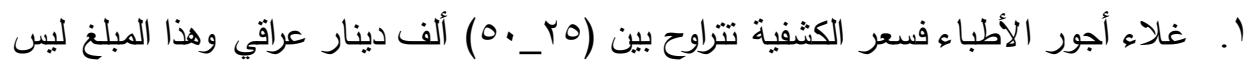
بقليل مما يلقي على كاهل رب الأسرة صعوبات مالية.

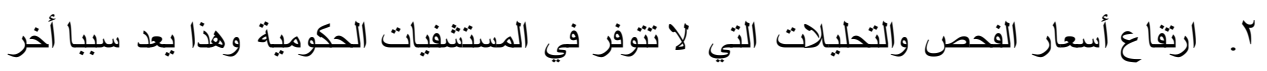
في عدم مراجعة الأطباء. 
العدد الأربعون

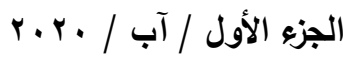

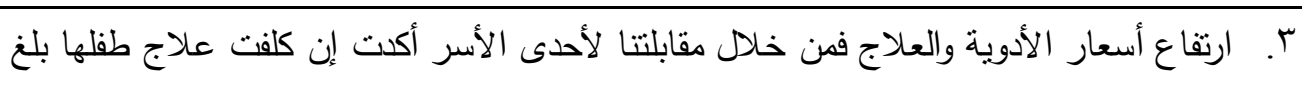

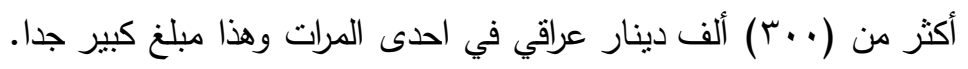

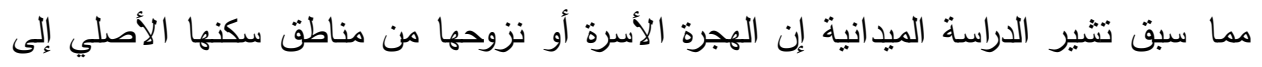

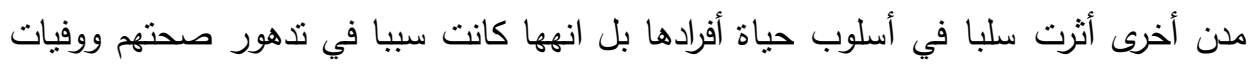
الكثير منهم ومن هنا نستطيع القول بتحقيق الفرضية الرئيسة للاراسة والموسومة (إن هجرة الأسرة وتغير مكان إقامتها كانت سببا في وفيات الأطفال).

\section{أهم النتائج والاستتتاجات}

توصل البحث إلى مجموعة من النتائج والاستتناجات أهمها: -

أولا: نتائج البيانات الأولية

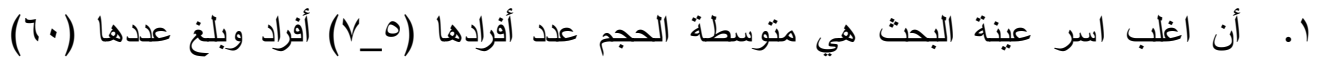

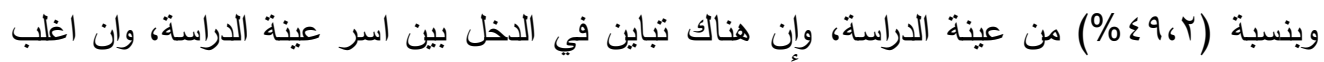

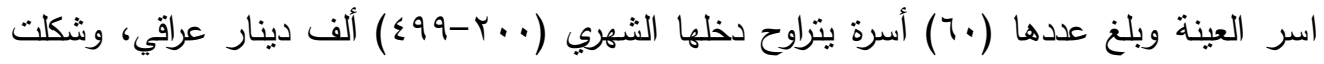

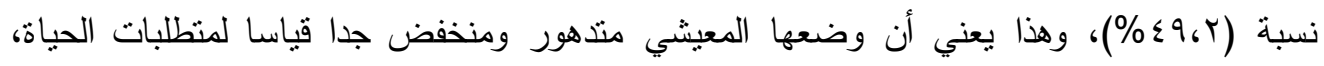
وعدد أفرادها. وأن اغلب الأسر التي حدثت فيها حالات وفيات الأطفال من عينة الدراسة، كان الآباء

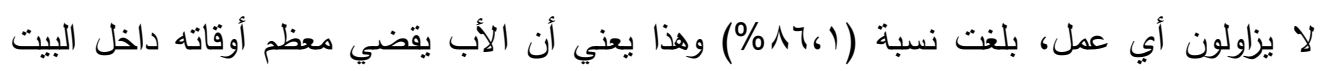
بسبب البطالة r. إن أعلى نسبة وهي (1، (\%) من عينة البحث اتخذت من المخيمات سكنا لها، وهي النسبة

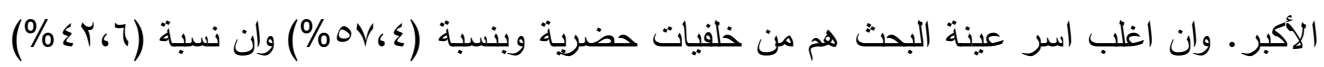

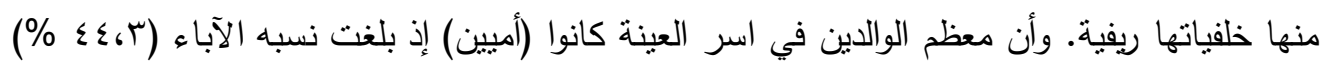
وهي الأعلى وان نسبه (9، (1\%) فقط حصلوا على التعليم الجامعي في حين بلغت نسبة الأمهات

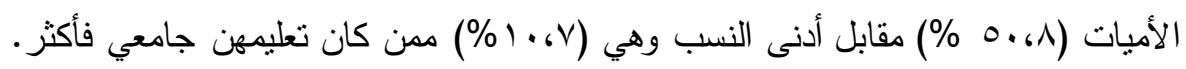

\section{ثانيا: البيانات الاجتماعية عن الطقل المتوفي}

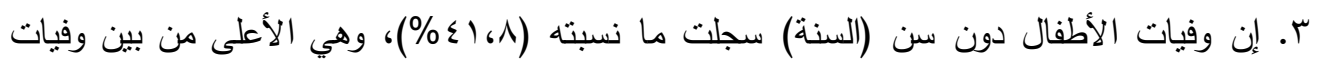

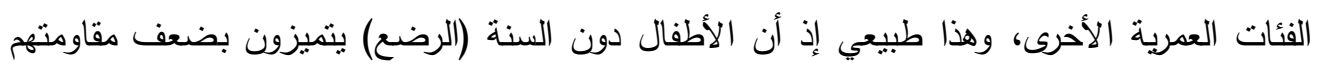

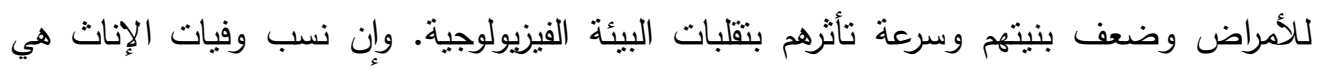


العدد الأربعون

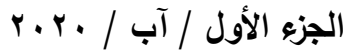

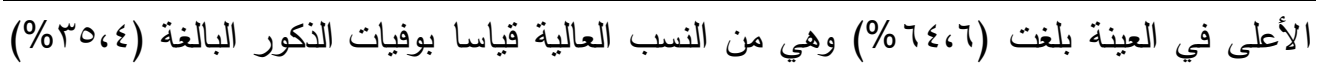
وهذا يدل على وجود فرق دال معنويا بين نسب وفيات الأطفال بحسب الجنس. ع. إن أعلى نسب وفيات الأطفال قد حدثت في المخيم الذي يسكنه غالبية المهجرين ذوي الدخول المنخفضة الذين ليس بإمكانهم دفع الإيجار وبنسبه ( حالة مرضه إلى المستشفى ، وان اكثر من نصف وفيات الأطفال في عينة الدراسة كانت بأسباب

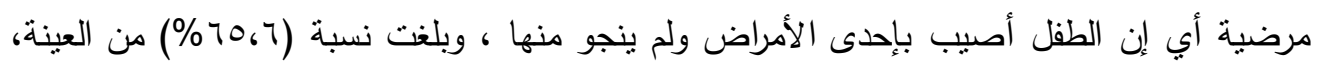
ويمكن إن نعزو ذللك إلى الأسباب التي سبق وان اشرنا اليها في الأسطر والصفحات السابقة التي تتمنل في ( عدم الإمكانية الاقتصادية للأسرة في علاج أطفالها، عدم توفر الرعاية الصحية في مناطق سكناها انتشار الأوبئة والأمراض في المخيمات السكنية، قلة الوعي الصحي والثقافي للأسرة . (أ.... مدواليك)... ه. إن أعلى النسب وهي (ץ،§؟\%) من الأطفال عولجوا منزليا أي قام أحد الوالدين بعلاجه بعيدا عن أي تشخيص طبي وان نسبة (7،7\%) وهي الأقل تم أخذهم إلى المرقي (السيد) وهذا بدوره يبين سوء الوضع ألمعاشي للأسرة من جهة وجهاها الصحي والثقافي لا سيما الأم والذي سيؤثر سلبا في حياة طفلها في المستقبل. وان غالبية اسر العينة لم تراجع المسنشفى قبل وفاة طفلها وبلغ عددها

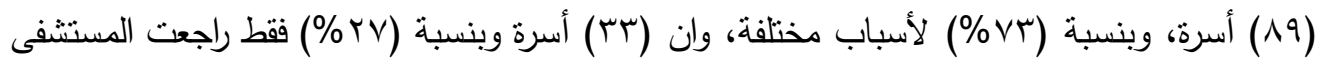
المراكز الصحية قبل وفاة طفلها إن هناك تباينا في إجابات العينة حول أسباب عدم مراجعتهم للمستشفى قبل وفاة طفلهم، وجاء السبب (عدم وجود مسنشفى في المخيم أو منطقة السكن) في المرتبة

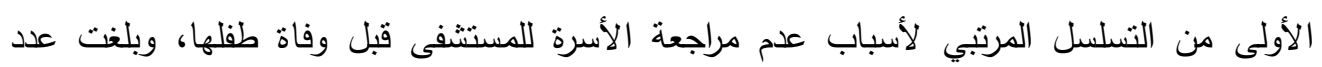
الإجابات (• (ع) إجابة.

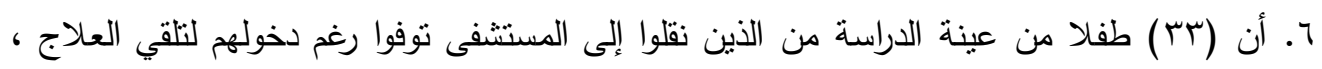
وهذا مؤشر على قصور الخدمات الصحية ونقص الأدوية والكوادر وارتفاع نفقات العلاج في المستشفى وهو احد أسباب الوفاة المتكررة في تلك الحقبة .وعن أسباب خروج الطفل من المستشفى مونى كانت منباينة وبلغ عدد الأطفال الذين غادروا المسنشفى بسبب الثفاء التام (ع) أطفال وبنسبة (1) وهي نسبة قليلة جدا وبلغ عدد الأطفال الذين غادروا المستشفى بسبب ارتفاع نفقة العلاج داخل المستشفى (1) أطفال وبنسبة (r/r\%\%)، وبلغ عدد الأطفال الذين غادروا المستشفى بسبب نقص الأدوية (r) أطفال وبنسبة (ع، بr\%) وهي الأعلى .وبلغ عدد الأطفال الذين غادروا 
العدد الأربعون

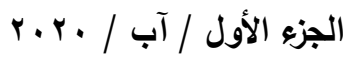

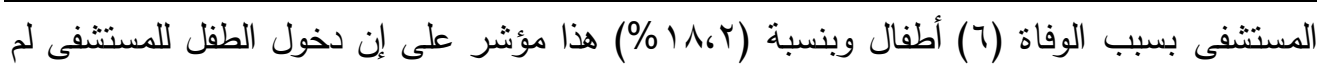
يساعد في تحسن حالته الصحية V. إن غالبية الأسر المبحوثة لم تراجع طبيبا مختصا عند مرض طفلها وقبل وفاته، إذ بلغ نسبتهم

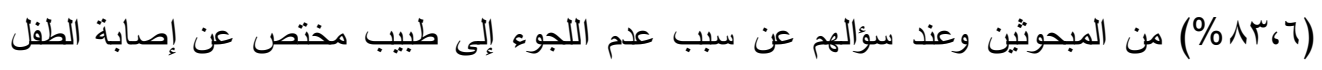

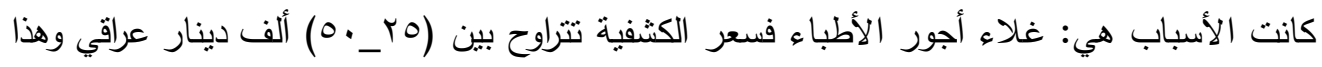

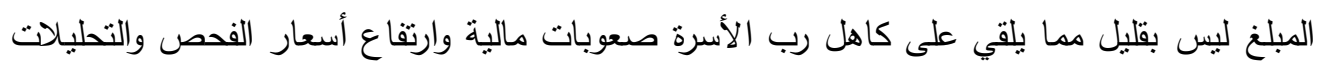

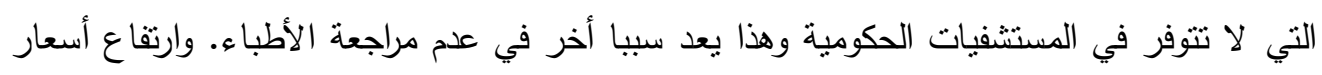

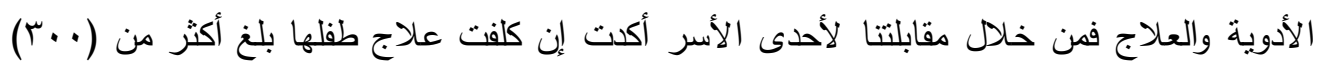
ألف دينار عراقي في احدى المرات وهذا مبلغ كبير جدا.

\section{التوصيات: يوصي الباحث بما يأتي}

1. الاهتمام بالأسرة المهجرة في إقليم كوردستان العراق من قبل الجهات العيات الحكومية ومنظمات

$$
\text { البتمع المدني. }
$$

r. توفير كافة مستلزمات الحياة الأساسية والني تمكن الأسر النازحة من العيش بعيدا عن المخاطر والأمراض من خلال توفير المنطلبات الصحية والغذائية لها.

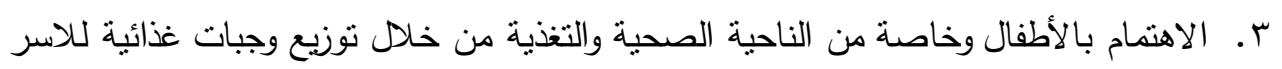

$$
\text { التي لديها أطفال. }
$$

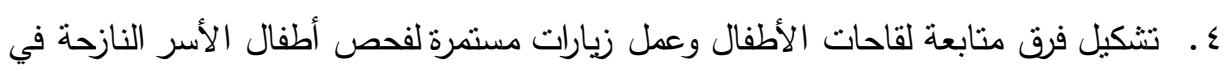

$$
\text { المخيمات أو في المناطق الأخرى. }
$$

ه. تأهيل والاهنمام الأكثر بواقع المخيمات التي تسكنها غالبية الأسر التي نزحت من المدن العراقية

$$
\text { إلى إقليم كوردستان. }
$$

7. . مخاطبة منظمات الأمم المتحدة للطفولة والمنظمات العربية المهتمة بالطفولة من اجل مساعدة

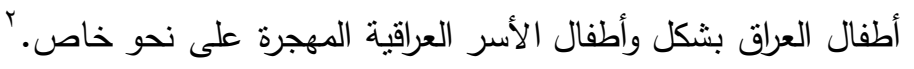


العدد الأريعون

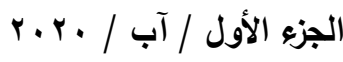

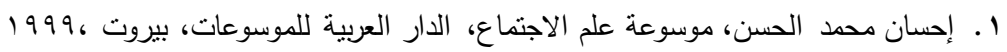

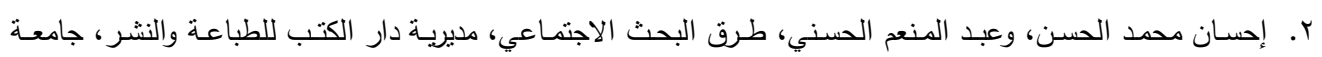

الموصل، 1919

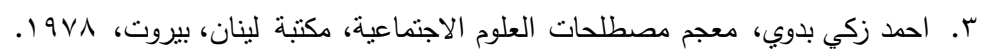

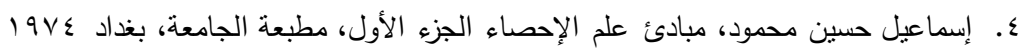

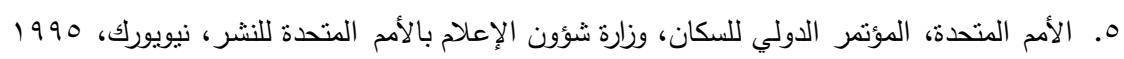

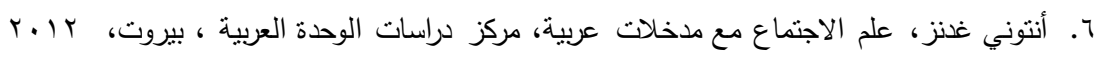

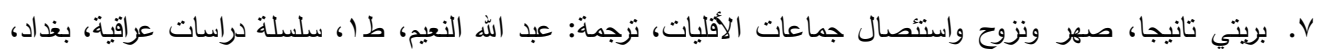

. r... 9

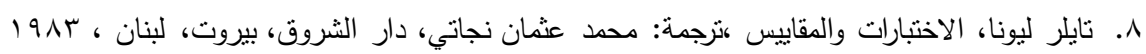

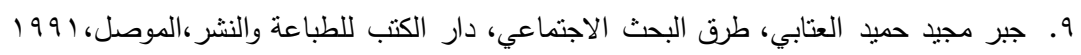

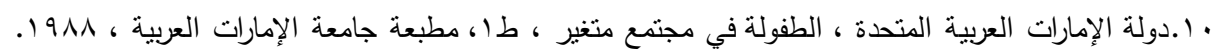

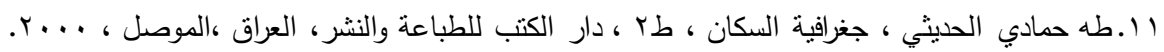

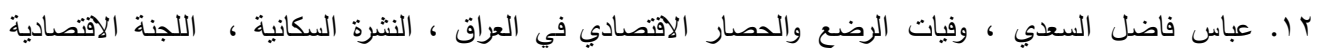

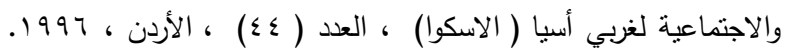

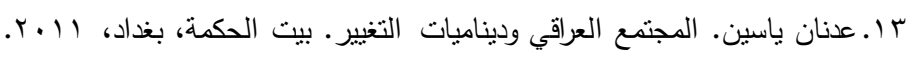

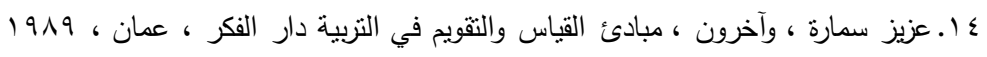

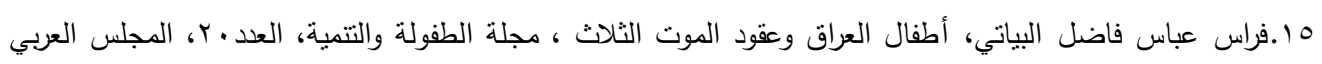

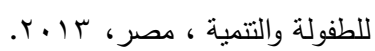

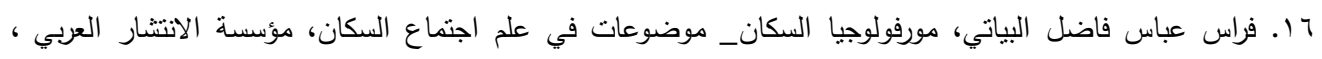

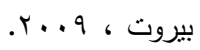

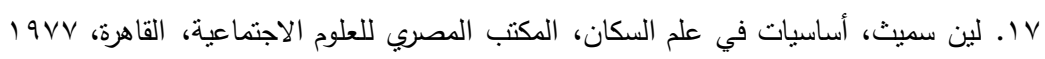

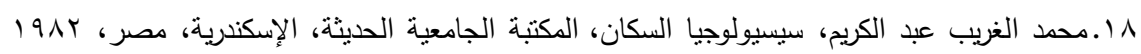

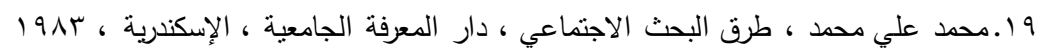

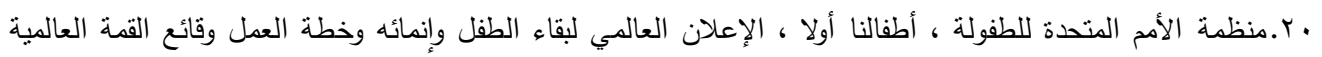

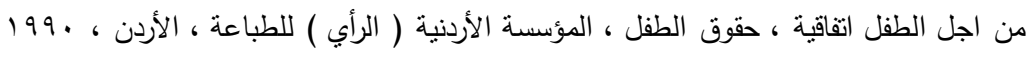

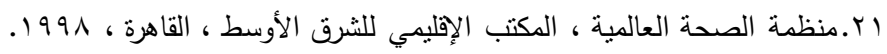

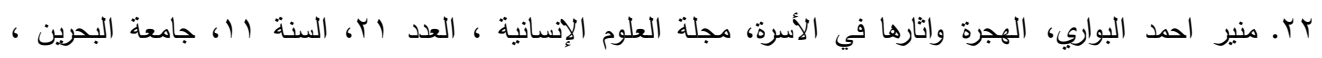
المنامة ، r Y ب. T.

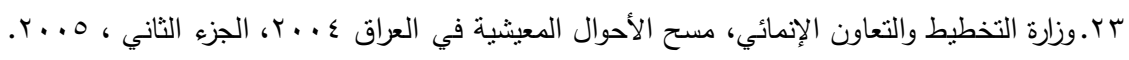




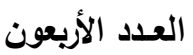

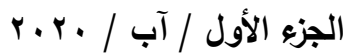
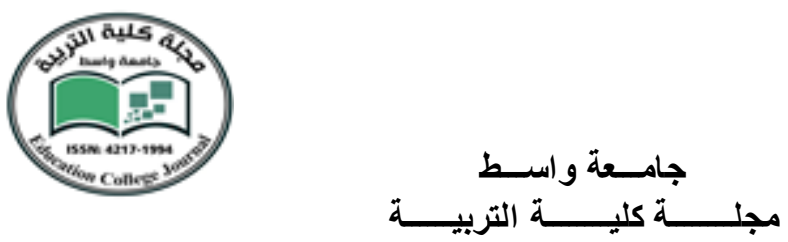

24. Emile. Durkhiem: Lafamille conjugale, revuc philosophique janvier-Ferrier. Paris, 1921.

25. Ogburn, W. and M. Nimkoff, "A handbook of society", fifth edition, rout ledge and kegan Ltd., London, 1967.

26. U. N., World Population Monitoring 1997, New York, 1998.

27. W.H.O .Official Recalled of world health Organization .N28. Third world health Assembly Geneva 8to 27 may.

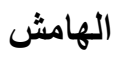

(') طه حمادي الحديثي ، جغرافية السكان ، طץ ، دار الكتب للطباعة والنشر، العراق ،الموصل ،

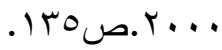

